\title{
Influence of Support Vector Regression (SVR) on Cryogenic Face Milling
}

\author{
Rao M. C. Karthik $\mathbb{D}^{1},{ }^{1}$ Rashmi L. Malghan $\mathbb{D}^{2},{ }^{2}$ Fuat Kara $\mathbb{D}^{3},{ }^{3}$ Arunkumar Shettigar $\mathbb{D}^{1},{ }^{1}$ \\ Shrikantha S. Rao, ${ }^{1}$ and Mervin A. Herbert ${ }^{1}$ \\ ${ }^{1}$ Department of Mechanical Engineering, National Institute of Technology, Mangalore, Karnataka, India \\ ${ }^{2}$ Department of Artificial Intelligence and Data Science, Angadi Institute of Technology and Management, Savagaon, \\ Karnataka, India \\ ${ }^{3}$ Department of Mechanical Engineering, Duzce University, Duzce, Turkey
}

Correspondence should be addressed to Rao M. C. Karthik; karthikmvit@gmail.com and Fuat Kara; fuatkara@duzce.edu.tr

Received 26 March 2021; Revised 12 July 2021; Accepted 26 July 2021; Published 5 August 2021

Academic Editor: Fernando Lusquiños

Copyright ( 2021 Rao M. C. Karthik et al. This is an open access article distributed under the Creative Commons Attribution License, which permits unrestricted use, distribution, and reproduction in any medium, provided the original work is properly cited.

\begin{abstract}
The paper aims to investigate the processing execution of SS316 in manageable machining cooling ways such as dry, wet, and cryogenic $\left(\mathrm{LN}_{2}\right.$-liquid nitrogen). Furthermore, "one parametric approach" was utilized to study the influence and carry out the comparative analysis of $\mathrm{LN}_{2}$ over dry and $\mathrm{LN}_{2}$ over wet machining conditions. Response surface methodology (RSM) is incorporated to build a relationship model among the considered independent variables (spindle speed: $(S, \mathrm{rpm})$, feed rate $(F, \mathrm{~mm} /$ $\mathrm{min})$, and depth of cut $(\mathrm{doc})(D, \mathrm{~mm}))$ and the dependent variable (surface roughness $(\mathrm{Ra}))$. Since there is the involvement of more than one independent variable, the generation of regression equation is "multiple linear regression." Based on the attained coefficient value of the independent variable, the respective impact on surface roughness is identified. The results of comparative analysis of $\mathrm{LN}_{2}$ over dry and $\mathrm{LN}_{2}$ over wet machining states revealed that $\mathrm{LN}_{2}$ machining yielded better surface finish with up to $64.9 \%, 54.9 \%$ over dry and wet machining, respectively, indicating the benefits of $\mathrm{LN}_{2}$ for achieving better Ra. The benchmark function of the proposed mode hybrid-bias (BNN-SVR) algorithm showcases the propensity to emerge out of the local minimum and coincide with the optimal target value. The performance of the (BNN-SVR) is a prevalent new ability to fetch the partially trained weights from the BNN model into the SVR model, thus leading to the conversion of static learning capability to dynamic capability. The performances of the adopted prediction approaches are compared through a range of attained error deviation, i.e., (RA: 3.95\%-8.43\%), (BNN: 2.36\%-5.88\%), (SVR: 1.04\%-3.61\%), respectively. Hybrid-bias (BNN-SVR) is the best suitable prediction model as it provides significant evidence by attaining less error in predicting Ra. However, SVR surpasses BNN and RSM approaches because of the convergence factor and narrow margin error.
\end{abstract}

\section{Introduction}

SS316 stainless steel has arisen and plays a vital role in manufacturing automotive, aerospace, valves, pipes, medical, coastal architectural fittings, marine, chemical industries, thermal power plants, mining industries, etc. The chemical structure of SS316 encloses an accumulation of molybdenum, adding the enriched corrosion resistance property. Despite their colossal application, during the machining of SS316, numerous challenges arise in terms of detrimental and achieving better surface integrity. Surface integrity is utilized in assessing the nature of parts. It likewise influences a few practical characteristics of parts w.r.t. to friction between the tool and work samples, tool wear, heat transmission, and the ability to distribute and hold a lubricant, coating, etc. Thus, surface quality expectation assumes a huge part in the machining business for the appropriate determination and control of machining boundaries and enhancement of cutting conditions. The introduction section is illustrated in two subsections, first towards the cryogenic machining and impact of cutting fluids over response parameters and in the second section, 
involvement of prediction techniques and estimation of the performance of these forecasting techniques.

Hegab et al. [1] proposed a calculation to assess maintainability towards machining methods. It incorporates each of the 4 life cycle phases of machining (pre, producing, use, and post) to assess sustainability. Later, Khanna et al. [2] utilized this calculation to think about the supportability of the LCO2 strategy with customary machining procedures. Khanna et al. [3] (LCA of dry, flood, $\mathrm{LN}_{2}, \mathrm{LCO} 2$ ) utilized the ReCiPe 2016 midpoint $(\mathrm{H})$ strategy as far as biological effect and energy utilization. They recognized $\mathrm{LN}_{2}$ as the best cooling strategy when contrasted with dry, flood, and LCO2 strategies. Shah et al. [4] earmark LCA for Inconel 718 boring under $\mathrm{LN}_{2}$ and $\mathrm{LCO} 2$ conditions. They utilized ReCiPe 2016 midpoint $(\mathrm{H})$ strategy to examine the effects on the assets, laborers' wellbeing, environment, etc. Ameliorated machining execution with lower power utilization was accounted for utilizing the LCO 2 condition when contrasted with the $\mathrm{LN}_{2}$ condition. Shape memory machining of FRC, PMMC, and NiTi is illustrated. The cutting of FRP composites presents numerous difficulties, for example, fiber tearing, delamination, fiber pullout, and dimensional errors in machined parts [5]. It can be presumed that cryogenic treatment effectively enacts 5083 alloy machinability and its mechanical properties. The performance of cryogenic treatment on 5083 alloys is measured w.r.t. tensile properties, thrust force, tool wear, and surface topography [6].

There is a need to promote the use of sensible LN2 and hybrid machining innovations in the assembly industry worldwide, highlighting the advantages. The outline of inhouse created $\mathrm{LN}_{2}$ and hybrid machining strategies is introduced. Different difficulties and future necessities w.r.t. to $\mathrm{LN}_{2}$ and hybrid machining methods are illustrated [7]. In the study, the effect of LN2 on the surface quality, grain structure and microhardness of AZ31C magnesium alloy was investigated. A huge enhancement towards surface quality was found in the cryogenic turned examples. With cryogenic machining, greater microhardness was achieved, i.e., 98.6 HV from 53.7 HV [8].

Khanna et al. [9] examined machinability and supportability of Nimonic 90 crossbreed turning when contrasted with $\mathrm{LN}_{2}$ turning. They revealed better execution utilizing CUAT than $\mathrm{LN}_{2}$, turning as far as surface quality and energy utilization. The creators likewise announced lesser fossil fuel byproducts on account of CUAT when contrasted with the $\mathrm{LN}_{2}$ turning procedure. Patel et al. [10] analyzed the execution of Nimonic 90 under wet and LCO2 conditions. A superior surface completion was acquired utilizing wet turning. Additionally, force utilization was escalated and developed chip fragility through the usage of LCO2 when contrasted with wet conditions.

Zhao et al. [11] proposed a cryogenic framework that empowers movable temperature scope of $20-196^{\circ} \mathrm{C}$. They blended compressed air in with $\mathrm{LN}_{2}$ to various extents to attain the necessary temperature. $\mathrm{LN}_{2}$ was utilized at a critical factor beneath $0.1 \mathrm{MPa}$. The creators uncovered a critical impact of cutting conditions on chip morphology and serrated attributes. Later Zhao et al. [12] investigated the processing execution of Ti6Al4V through dry and $\mathrm{LN}_{2}$ states.
The creators detailed higher miniature hardness and expanded excess compressive pressure utilizing cryogenic processing compared to dry processing. A detailed illustration was apropos lessening apparatus wear, fossil fuel byproducts, and surface quality under $\mathrm{LN}_{2}$ conditions as assimilated to ordinary machining $[13,14]$.

An overview of the other introduction part (second section) demonstrates a wide range of prediction methodologies used to predict surface finish. Gupta [15] studied tool wear, surface roughness to calculate necessary power requirements on cutting time, cutting speed, and feed rate. The achieved data was applied to develop models employing response surface methodology (RSM), ANN, and support vector regression (SVR) strategies. The output emphasized ANN and SVR models yielded higher accuracy compared to the RSM model. RSM was used to study the impact of input attributes on response attributes illustrated in [16-18]. Various analyses of techniques to predict the surface finish in machining procedures are mentioned in [19]. Regression analysis (RA), design of experiments (DOE), and neural network models were used to solve the problem associated with the prediction of surface quality in milling.

Meanwhile, for tool wear Bayesian SVM and Bayesian multilayer perceptron's method used [20] for tool fracture findings, SVM methodology was implemented for monitoring the rising of tool fracture illustrated [21, 22]. It is also reported in the literature that the Bayesian-SVR combination is also implemented in finding a better prediction accuracy rate [23]. Asilturk, the coefficient of assurance (R2), was determined for every method involved in the study, as R2 plays a vital role and acts as a measure to carry out forecast precision. A comparative study was made among ANN and SVR in order to calculate prediction performance.

Backpropagation neural network method is used to perform prediction accuracy in milling $[24,25]$. The prediction model was developed using Bayesian neural network (BNN) and support vector regression (SVR) techniques to predict tool wear and tool fracture in face milling operation [26]. In turning operations of non-corrosive steel, surface quality and machining temperature were estimated using the ANFIS model [27]. ANN and SVR models were illustrated to predict the cutting force and surface roughness in turning 4140 steel [28]. In a different study, surface quality and cutting forces were estimated in slot milling of 7075-T6 aluminum alloy with ANN and SVR strategies [29]. Additionally, in the literature, very little work has been conducted with face milling operation on AISI 316 incorporated with cryogenic machining along with soft computing techniques [30]. The literature suggests that to achieve desired "Ra," a blend of spindle speed, feed rate, and the doc is the best attribute combination [31-34].

The shared data were proposed to assign the weights, where outcome represents the forecast after effects superior to results acquired by equivalent loads and standard predisposition loads [26]. The strategies referenced above are broadly applied in weight assurance, and comparative cases are acquired after closeness estimation. Be that as it may, these techniques above still come up short on the versatile capacity and cannot ensure the actual significance. Artificial 
neural network (ANN) manages the nonlinear issue effectively; numerous works were centered around the ANN model to discover the loads. Loads accepted using the ANN technique, and the outcomes were palatable in a fundamental oxygen heater (BOF) [35]. Relich [36] illustrated the assurance of the weight utilization in ANN strategy through a new item advancement measure (NPD). Further, ANN was prepared by gradient descent with a versatile ability to learn rate calculation. The outcomes exhibited that ANN helps CBR to get more comparative cases contrasted regression model (RA).

A few researchers presumed support vector regression (SVRM) strategy to build up a case reuse model in the expectation of a fundamental oxygen heater (BOF) [26]. The outcomes represented wise execution than the traditional way of reusing the model. Nonetheless, the neural organization has lackluster showing confronting few comparable cases. Interim, the SVR model cannot manage information with commotion well, so the method needs to be prepared from the start utilizing comparative prototypes from which learning calculation is expected to acquire the certified model. With respect to state recovery and state reuse, it is vital to track down a suitable learning calculation for upgrading the recovery and reexamine models.

Mathew et al. [27] discussed the comparative prediction analysis among ANN and ANFIS in tempered welding of steel. A comparative study illustrated that the ANFIS approach was prevalent compared to ANN due to its ability to achieve local interpolation. Ghosh et al. [37] illustrated the utilization of the ANN model to carry out a surface quality prediction in milling. The prepared ANN model forecast execution is best compared to the statistical prediction approach RSM. Natarajan et al. [38] acknowledged surface quality forecast evaluating through ANFIS strategy in milling. The outcomes showcased that the ANFIS procedure attains better forecast results as analyzed to the ANN model.

However, the prediction of response attribute Ra was not derived concentrating on "bias" specific parameters in their works as it is difficult for conventional modeling methods to take bias-Ra into interpretation. But Ra plays a vital role in identifying several functional attributes of parts. To fulfil the criteria, a suitable intelligent model based on "hybrid-bias" derival of weights is significant to predict surface roughness $(\mathrm{Ra})$ in various machining environments.

Moreover, based on topology prediction of engineering processes, substantial research is reported on various prediction strategies. ANN is used to monitor and predict surface finish associated with Ra value, with trial or random assignment of weights, thus leading to falling into "pit or local optimum." However, none of those neural networks were tried to overcome the said flaw through "hybrid-bias" derival of wights and assigning it to other approaches to predict the $\mathrm{Ra}$ as an output. Thus, the concern is to find the role of independent variables on dependent variables through hybrid-bias derivation of BNN into SVR to other commonly used predictions.

Interim, SVR model was unable to manage the noisy data well, and so the model should be well trained prior to comparable cases as to acquire the certified model.
Concerning case recovery and case reuse, it is essential to track down a suitable learning calculation for enhancing the recovery and modify models. So there is a need for a hybridbias (BNN-SVR) model. The results attained showcase that the BNN-SVR model predicts surface roughness with reasonably high accuracy compared to other similar studies described in the literature due to its ability to achieve better convergence and global optimum.

In brief, the present research explains the balance of process variables that simultaneously minimize the machining characteristics. ANN and machine learning (hybrid bias: BNN-SVR) models are proposed for the best selection of machining parameters and optimization of cutting conditions. Figure 1 represents the research methodology used in the current study to understand the flow of work better.

In this work, an improved prediction technique hybridbias (BNN-SVR) method was proposed to assess surface roughness. The innovations exposed are as follows: firstly the BNN model to determine the relation logic of each dependent and independent attribute, second, assurance of local interpolation (exponential term value in a stable state), so that these weights can be transferred to SVR, and the last innovation was to foster hybrid-bias (BNN-SVR) model. The proposed model performs an accurate prediction of surface roughness, and it even avoids falling into local minima.

The remnant of this paper is organized as follows: Section 1 describes one-factor approach (OFA) for experimental illustration w.r.t. to the usage of different mediums in machining, Section 2 describes RSM approach to study the impact of the dependent variable on independent variable using multiple regression equation. Section 3 describes the implications of evolutionary prediction technique BNN and implementation of hybrid-bias (BNNSVR) method and its methodology to achieve better convergence and global optimum. In Section 4, performance verification of the proposed hybrid-bias (BNNSVR) method is performed through comparative study. Section 5 concludes this study.

\section{Materials and Methods}

Stainless Steel SS316 (AISI 316) was used as a sample workpiece with the size $100 \mathrm{~mm} \times 40 \mathrm{~mm} \times 10 \mathrm{~mm}$. The face milling operation was conducted on CNC vertical Spark DTC milling machine $[39,40]$, utilizing cutter diameter $50 \mathrm{~mm}$ WIDIA M690 with PVD coated inserts TiAlNSDMT 1204PDR-MH-PA120. The experiments were carried for three machining conditions: conventional wet, dry, and $\mathrm{LN}_{2}$ (cryogenic).

It is observed from the literature that the coated inserts perform better in comparison with uncoated inserts. The coating of TiAlN is in the range of $1-3 \mu \mathrm{m}$ and can be up to $4 \mu \mathrm{m}$. The coated insert not only increases the tool life up to 10 times but also develops an ability to withstand higher cutting temperatures and avoid oxidation. $\mathrm{LN}_{2}$ as a cutting fluid will control the excess heat developed in the machining zone [39]. TiAlN and AlTiN are widely used inserts to machine stainless steel to avoid tool wear and oxidationrelated issues [40]. 


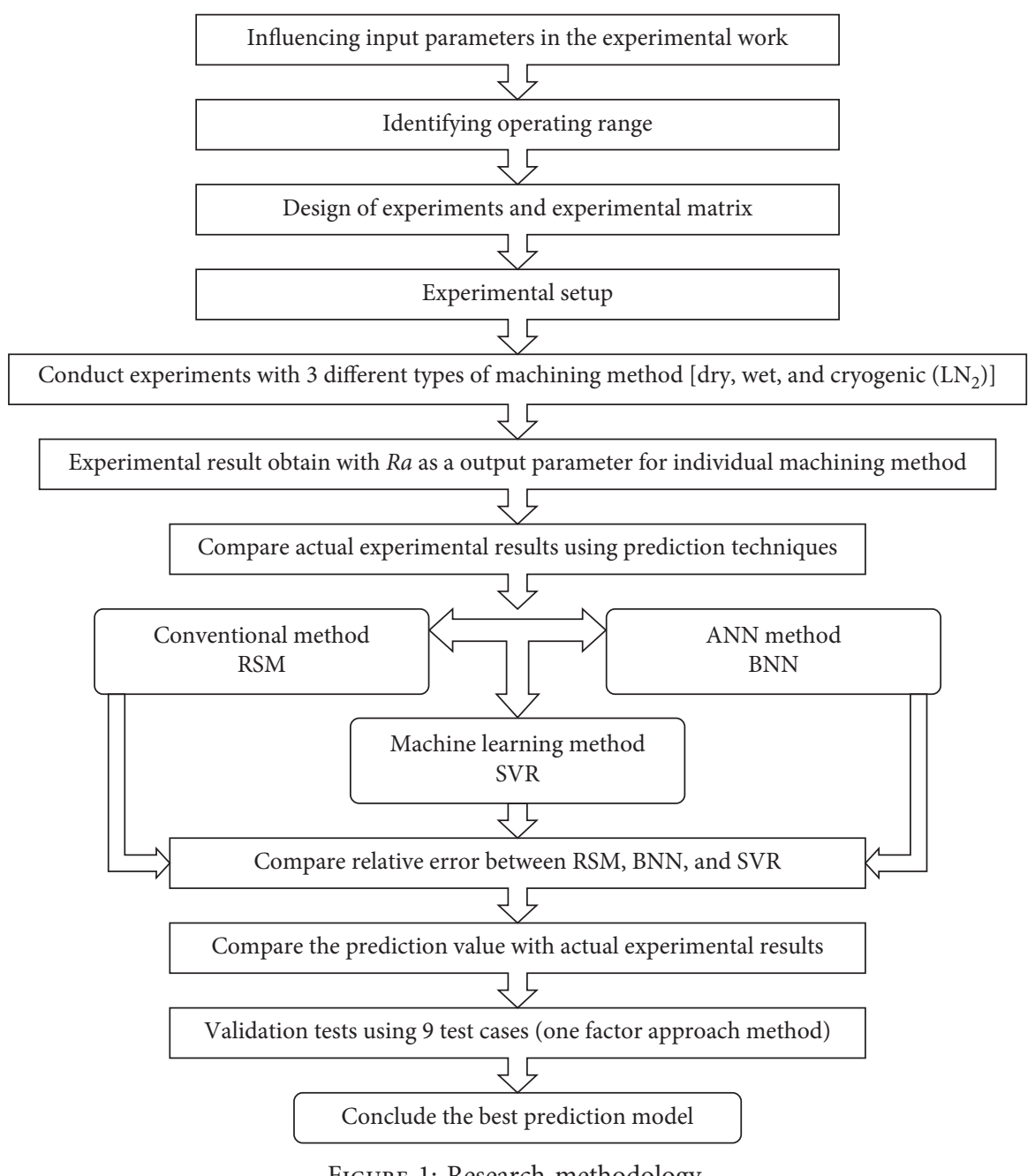

FIgURE 1: Research methodology.

The experiments with " $S$ " in $\mathrm{rpm}$, " $F$ " in $\mathrm{mm} / \mathrm{min}$, and " $D$ " in mm ranges are selected based on the tool insert working range specifications as specified by the tool insert manufacturer. The operating range (upper and lower range) was confirmed by carrying out a set of preliminary machining experiments with a low and high working range of tool inserts for $S, F$, and $D$. The operating range needs to be taken care of by looking into associated problems, such as vibration during machining, chatter effect, increased cutting temperature and tool wear, tool breakage, and deteriorating Ra. Based on these limitations, the assumption has been made within the tool insert working range specification, and further on, DOE was decided for the study.

Figure 2 exhibits the flow of the article. The SS316 composition is represented in Table 1. The machining variables and range are represented in Table 2, depending on tool insert specifications by the manufacturer. Figures 3(a) and 3 (b) represent scanning electron microscope (SEM) image and element composition weight (\%) of workpiece SS316, respectively. Figures 3(c) and 3(d) represent the energy dispersive X-ray spectroscopic (EDS) images of SS316 using scanning electron microscope (SEM) with color and black and white scale, respectively.
In this study, the one-factor approach (OFA), also known as the one factor at a time method (OFAT), is utilized to design the experiments, in which out of three input parameters (cooling type (CT) excluded) one input parameter is varied. Table 2 represents different levels (range) and input parameters. In this study, the experiments were conducted with three different cases, such as case (i) constant spindle speed maintained at $2000 \mathrm{rpm}$ and feed rate and doc varied from low to high operating levels, case (ii) constant doc of $1 \mathrm{~mm}$ preserved and spindle speed and feed rate altered among the low and high operating range, and case (iii) constant feed rate of $450 \mathrm{~mm} / \mathrm{min}$ retained and spindle speed and doc changed between low to high machining levels.

Table 3 represents 9 test cases with output response as a surface roughness $(\mathrm{Ra})$, resulting in comparison between different machining conditions such as dry, wet, and $\mathrm{LN}_{2}$ and also shows the advantage in percentage reduction of the $\mathrm{LN}_{2}$ method of machining when compared to dry and wet machining individually. The same results are indicated using Figures 4 and 5, respectively.

Figure 4 exhibits the surface roughness ( $\mathrm{Ra}$ ) values attained through experimental work using three different 


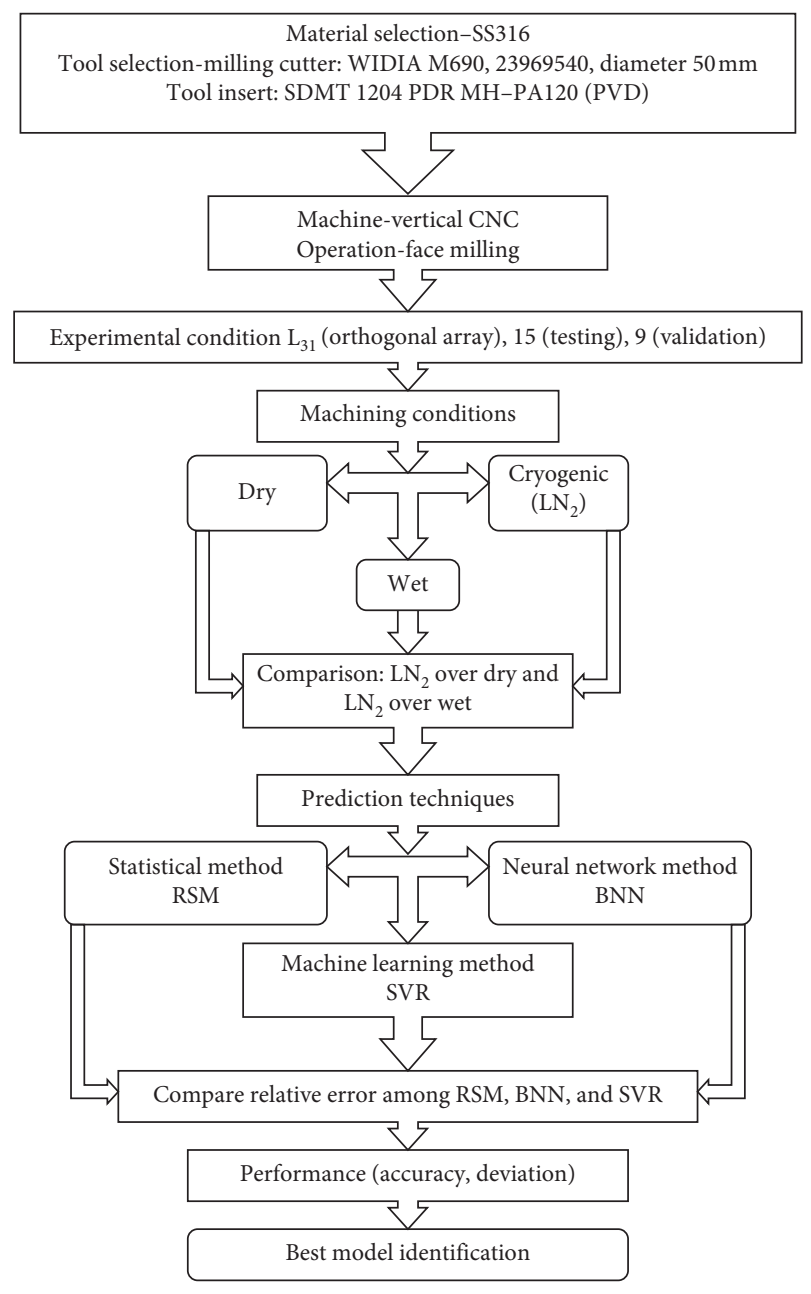

FIgURE 2: Structure of the article.

TABle 1: Composition ranges of elements in SS316 grade.

\begin{tabular}{lccccccccc}
\hline Grade & $\mathrm{C}$ & $\mathrm{Mn}$ & $\mathrm{Si}$ & $\mathrm{P}$ & $\mathrm{S}$ & $\mathrm{Cr}$ & $\mathrm{Mo}$ & $\mathrm{Ni}$ & $\mathrm{N}$ \\
\hline 316 & 0.08 & 2.0 & 0.75 & 0.045 & 0.03 & 18.0 & 3.00 & 14.0 & 0.1 \\
\hline
\end{tabular}

TABLE 2: The machining variables and level.

\begin{tabular}{lccc}
\hline Machining parameters & \multicolumn{3}{c}{ Levels } \\
& High & Middle & Low \\
\hline CT & $1\left(\mathrm{LN}_{2}\right)$ & $0(\mathrm{Wet})$ & -1 (Dry) \\
$F(\mathrm{~mm} / \mathrm{min})$ & 550 & 450 & 350 \\
$D(\mathrm{~mm})$ & 1.5 & 1 & 0.5 \\
$S(\mathrm{rpm})$ & 3000 & 2000 & 1000 \\
\hline
\end{tabular}

machining methods such as conventional dry, wet, and $\mathrm{LN}_{2}$ (cryogenic). Similarly, Figure 5 comments on the graph, highlighting the dominance of $\mathrm{LN}_{2}$, i.e., cryogenic method on conventional wet and dry machining methods in percentage deviation with 9 test cases.

Figure 6(a) shows the schematic representation of the experimental setup with different parts involved in the cryogenic machining technique. Figure 6(b) illustrates the proposed hybrid-bias (BNN-SVR) method. Figure 6(b) shows that the BNN-SVR performance is the prevalent new ability to fetch the partially trained weights from the BNN model into the SVR model, thus in the conversion of static learning capability to dynamic capability. The performance of hybrid-bias (BNN-SVR) surpasses the performance of BNN and RSM by achieving greater convergence and minor deviation error, whereas Figure 7 represents the authentic experimental images with different instances of the experimental work such as (a) full cryogenic experimental setup used with different components, (b) experimentally used milling cutter and tool inserts with specifications, (c) nozzle positioning setup to the tool and workpiece (machining zone) interface before the experiments, and (d) $\mathrm{LN}_{2}$ sprayed to the machining zone during the experiments.

2.1. Surface Roughness. The "MITUTOYO SURFTEST SJ301 " surface roughness tester is utilized to measure the surface roughness, as shown in Figures 8 and 8(b).

The "Ra" is the assessment factor used for surface roughness, also known as arithmetic average (AA) in micrometers $(\mathrm{mm})$ equation [41]:

$$
R a=\frac{1}{l} \int_{0}^{l}|y(x)| \mathrm{d} x .
$$

Based on the extraction of data digitally, the trapezoidal rule replaces an integral part, and "Ra" could be approximated based on the following equation $[3,38-40]$ :

$$
R a \approx \frac{1}{n} \sum_{i=1}^{n}\left|y_{i}\right|
$$

where "Ra" is the AA deviation from the mean line (in mm), $y$ is the ordinate of the profile curve, and $l$ is the sampling length. In measuring the surface roughness, the measurement has taken in three various localities, and the mean value was considered the output response value. The specifications of the surface roughness tester are as follows.

Tip radius of the stylus is $2 \mu \mathrm{m}$, force applied by the stylus is $0.75 \mathrm{mN}$, and stylus speed is $0.25 \mathrm{~mm} / \mathrm{s}$.

\section{Modeling Methods}

3.1. Regression Analysis (RA). The present study had investigated the RSM- (regression analysis-) based design of experiments for the possible arrangement of ranges for " $S$ " in $\mathrm{rpm}$ (Spindle speed), " $F$ " in $\mathrm{mm} / \mathrm{min}$ (Feed-rate), and " $D$ " in $\mathrm{mm}$ (Depth of cut) and CT (coolant type). To attain maximization/minimization of the output, the association between outputs processes with input judgment variables is mapped $[42,43]$. From the first-order model's equation (3), the second-order model is derived $[44,45]$.

$$
\begin{aligned}
\widehat{y_{2}}= & y-\varepsilon=b_{0} x_{0}+b_{1} x_{1}+b_{2} x_{2}+b_{3} x_{3}+b_{4} x_{4} \\
& +b_{11} x_{1}^{2}+b_{22} x_{2}^{2}+b_{33} x_{3}^{2}+b_{44} x_{4}^{2}+b_{12} x_{1} x_{2} \\
& +b_{23} x_{2} x_{3}+b_{13} x_{1} x_{3}+b_{14} x_{1} x_{4},
\end{aligned}
$$

where $\widehat{y_{2}}$ is the estimated response, $y$ is the dummy factor in logarithmic scale $x$ measured as $x_{0}=1, \varepsilon$ is the experimental error, and $b_{0}-b_{4}$ are the factor values estimated from the $\beta$ 


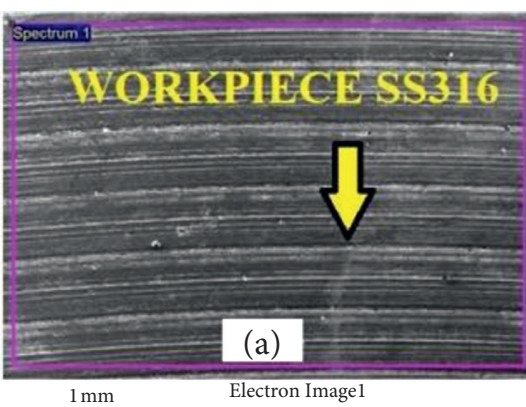

Quantitative results Element composition weight

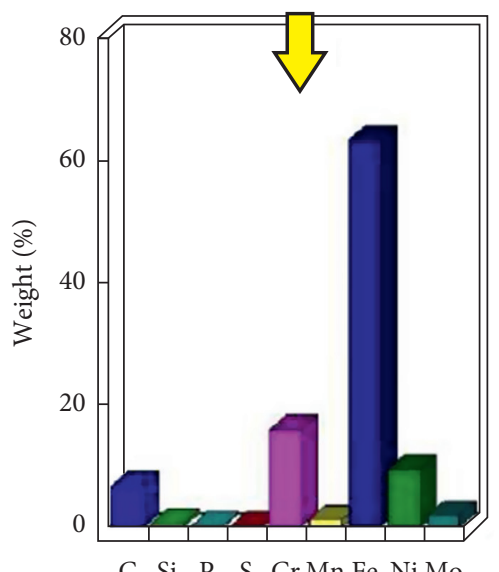

(b)

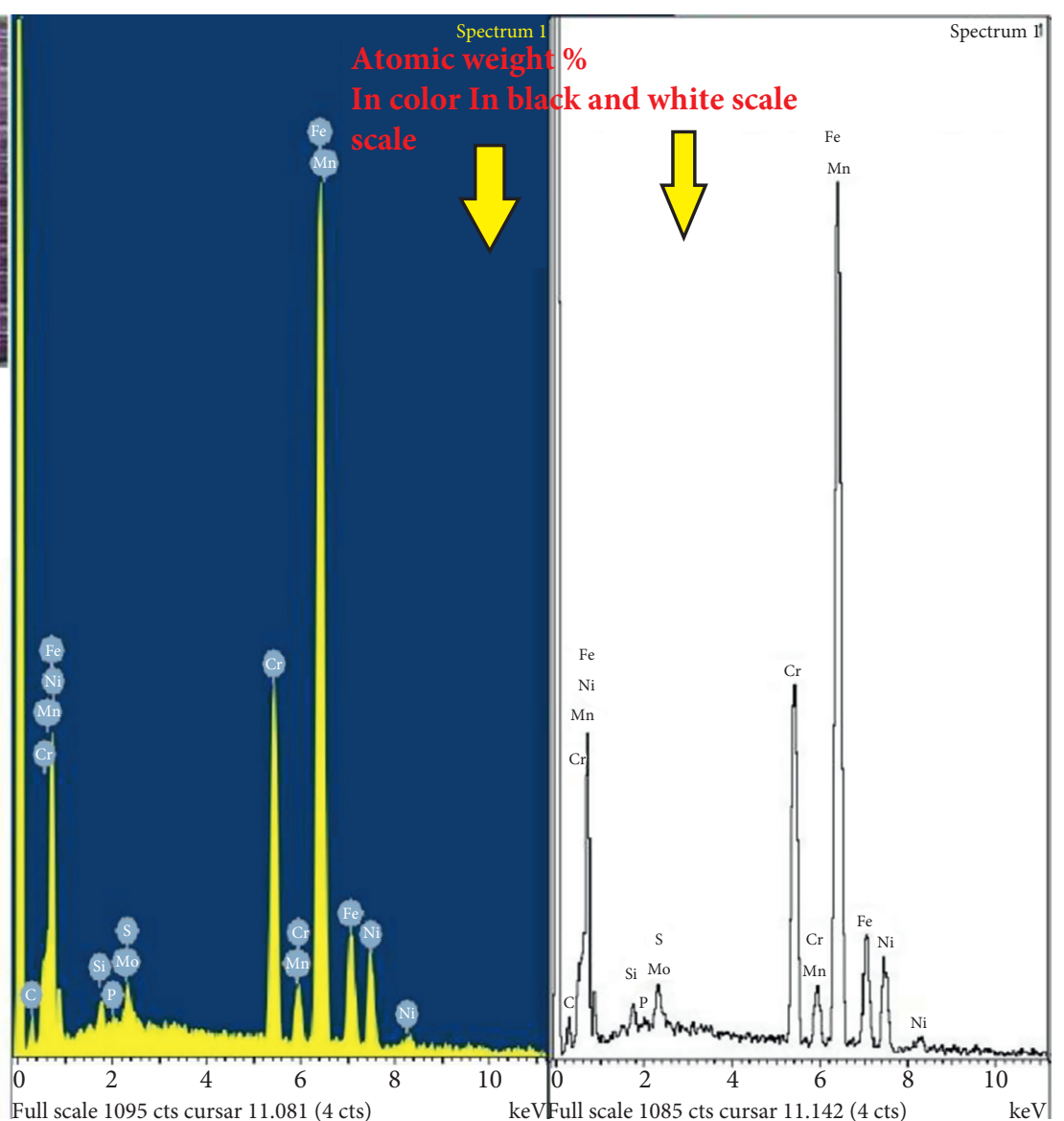

(c)

(d)

FIGURE 3: SEM image of the EDS spectra of SS316. (a) SEM image of workpiece SS316. (b) Element composition weight (\%) of workpiece SS316 using EDS. (c) SEM image of the EDS spectra of SS316 in color scale. (d) SEM image of the EDS spectra of SS316 in black and white scale.

TABLE 3: Experimental dataset: one-factor approach.

\begin{tabular}{|c|c|c|c|c|c|c|c|c|}
\hline \multirow{2}{*}{ Sl. no } & \multicolumn{3}{|c|}{ Experimental } & \multicolumn{3}{|c|}{ Surface roughness $(\mu \mathrm{m})$} & \multicolumn{2}{|c|}{$\%$ reduction } \\
\hline & $S(\mathrm{rpm})$ & $F(\mathrm{~mm} / \mathrm{min})$ & $D(\mathrm{~mm})$ & Dry & Wet & $\mathrm{LN}_{2}$ & $\mathrm{LN}_{2}$ over dry & $\mathrm{LN}_{2}$ over wet \\
\hline 1 & 1000 & 350 & 1 & 3.55 & 2.42 & 1.36 & 61.7 & 43.8 \\
\hline 2 & 1000 & 450 & 1 & 4.32 & 2.79 & 1.77 & 59.0 & 36.6 \\
\hline 3 & 1000 & 550 & 1 & 4.57 & 3.20 & 1.93 & 57.8 & 39.7 \\
\hline 4 & 2000 & 350 & 1 & 3.19 & 2.09 & 1.12 & 64.9 & 46.4 \\
\hline 5 & 2000 & 450 & 1 & 3.66 & 2.58 & 1.40 & 61.7 & 45.7 \\
\hline 6 & 2000 & 550 & 1 & 4.02 & 2.96 & 1.67 & 58.5 & 43.6 \\
\hline 7 & 3000 & 350 & 1 & 2.84 & 1.84 & 0.83 & 70.8 & 54.9 \\
\hline 8 & 3000 & 450 & 1 & 3.29 & 2.43 & 1.26 & 61.7 & 48.1 \\
\hline 9 & 3000 & 550 & 1 & 3.87 & 2.77 & 1.38 & 64.3 & 50.2 \\
\hline
\end{tabular}

parameters to be appraised for spindle speed ( $S$ in rpm), feed rate $(F$ in $\mathrm{mm} / \mathrm{min})$, doc ( $D$ in $\mathrm{mm})$, and coolant type (CT), respectively. Similarly $b_{11}-b_{44}$ are the interaction among terms. $x_{1}$ is the spindle speed $(S), x_{2}$ feed rate $(F), x_{3} \operatorname{doc}(D)$, and $x_{4}$ coolant type (CT) in the linear logarithmic conversion. $x_{1}^{2}-x_{4}^{2}$ are the quadratic factors, $x_{1} x_{2}, x_{2} x_{3}, x_{1} x_{3}$, and $x_{1} x_{4}$ are the interaction between two terms. The regression coefficients were obtained by the application of RA on the experimental-based data.
3.2. Bayesian Neural Network (BNN). The classification of BNN came under a feed-forward neural network and is used as a modeling tool for complex nonlinear problems. In the present research, the $\mathrm{BNN}$ model comprises three layers, such as input, hidden, and an output layer with 4,6 , and 1 neurons, respectively $[46,47]$. It is essential to identify the objective function based on the submitted dataset. Usually, the dataset contains $x$ and $y$, where $x$ is input and $y$ is the target vector. The unknown function is determined based on 


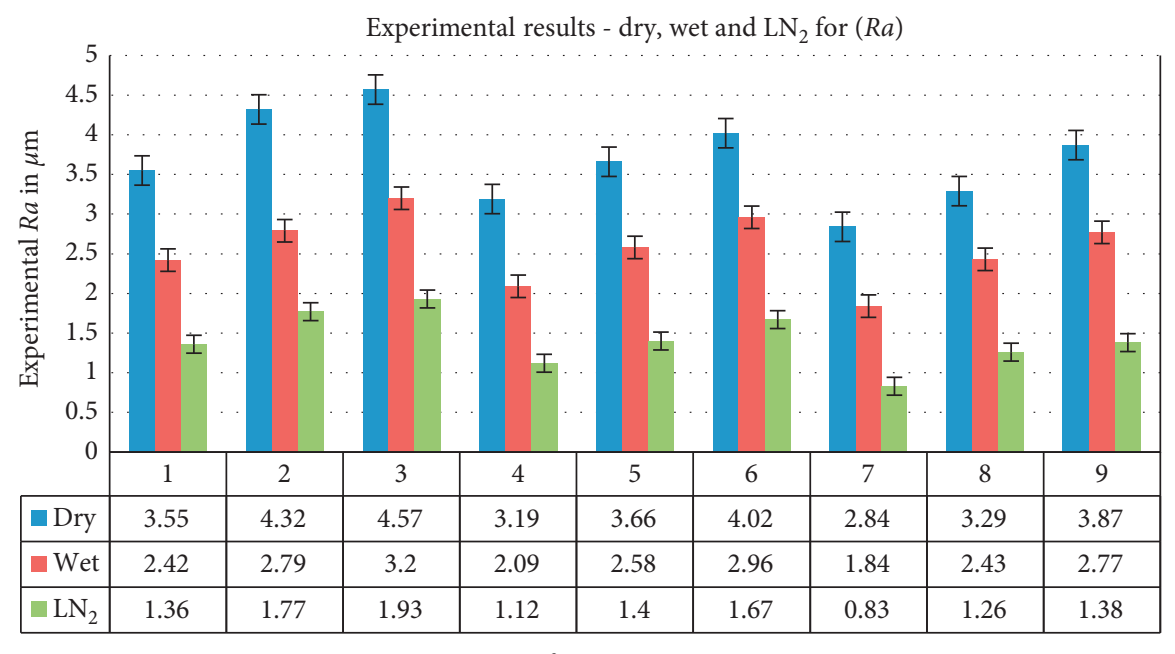

No. of experiments

Figure 4: Experimental results using OFA: dry, wet, and $\mathrm{LN}_{2}$ ( $\mathrm{Ra}$ in $\mu \mathrm{m}$ ).

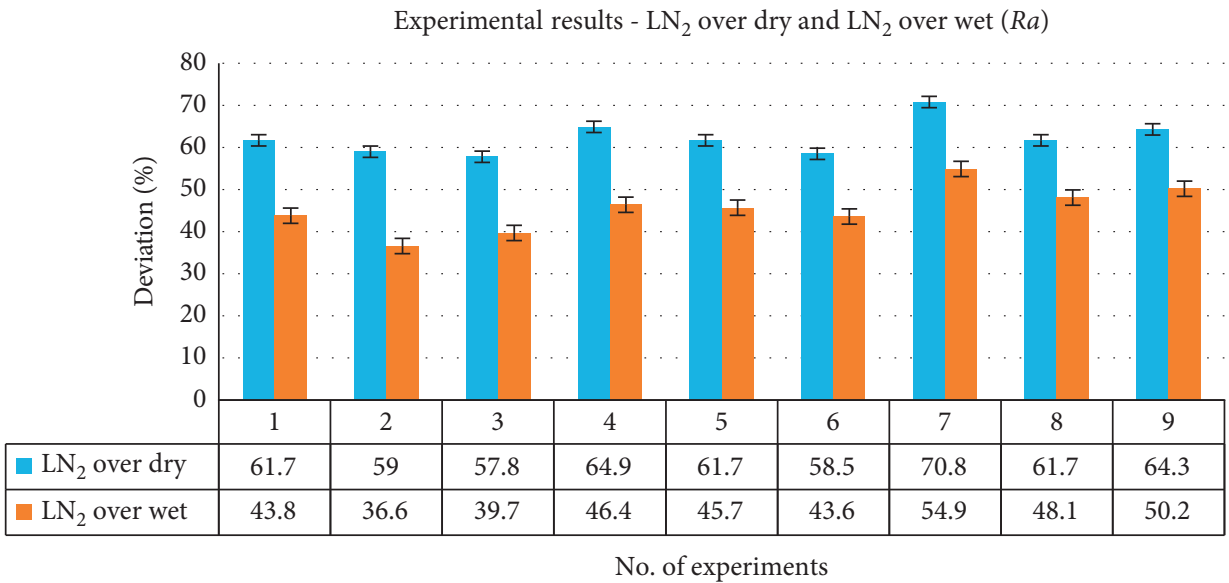

Figure 5: Percentage deviation in experimental results using OFA: $\mathrm{LN}_{2}$ v/s dry and $\mathrm{LN}_{2} \mathrm{v} / \mathrm{s}$ wet (Ra).

parameters vector $w$., which intern takes to nonlinear function that is $y(x, w)$. By identifying the variable $w$ indirectly, the $y(x, w)$ function can be concluded. Meanwhile, this process is called a learning and training process. The error function is minimized by adjusting the parameter $w$, which is called by name sum of squares error (SSE) [48]. Figure 9 represents the flow of steps carried in the ANN model to validate the input and output machining variables.

The numerical equations utilized to develop mathematical modeling of ANN are represented in Figure 9, and similarly, the equations used to develop RSM modeling are represented in equation (3). The ANN and RSM mathematical modeling is based on the preliminary experiments, which are as per the manufacturer's instructions on tool insert and workpiece machining range. Also, the experiments with the input parameters $S, F, D$ below or above the mentioned range of specifications for tool insert the result in deteriorating $\mathrm{Ra}$ and other machining issues like chatter, vibration, and excess cutting temperature [49-52].
BNN is incorporated in the current study as it determines the probabilistic nature of the learning process of the network. In BNN for weight adjustment, the regularization is considered as the prior distribution. In this study, Gaussian is used as a prior distribution while performing BNN. BNN usually controls the complexity of the network automatically, so the need for cross-validating the approach can be eliminated.

3.3. Support Vector Machine (SVM). SVM is usually used to carry out regression and classification tasks $[15,17,29]$. SVMs are referred to as kernel methods as they incorporate a class of algorithms. The highlighted properties of SVN are few adjusting parameters and generalization ability. In this study, the SVM concept was used to carry out a regression problem. Thus, it is said as support vector regression (SVR). Estimating the SVM accuracy lies in capacity $C$, kernel parameter, and insensitive region epsilon $\varepsilon$. The regression function was found with the help of many support vectors. 


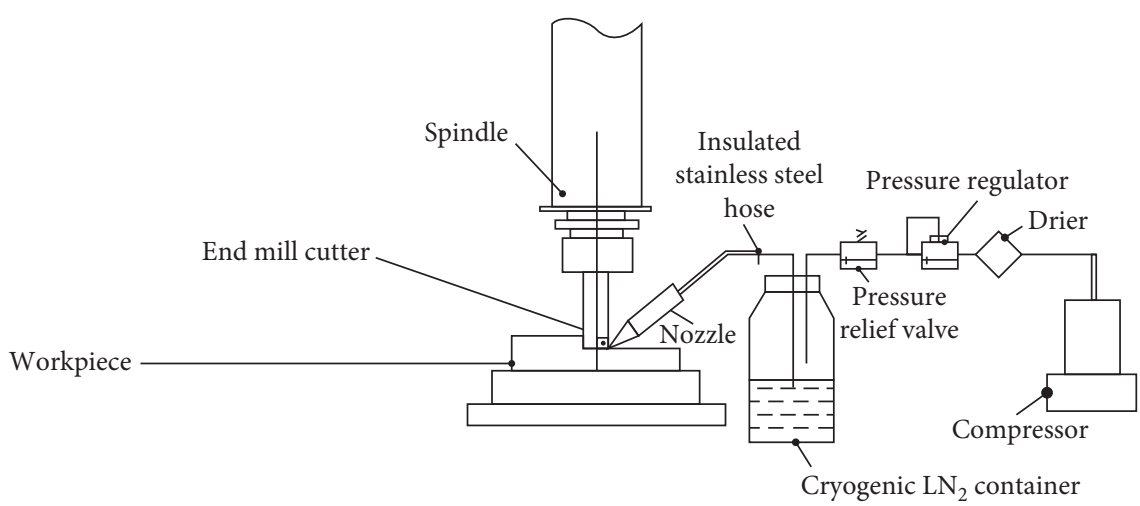

(a)
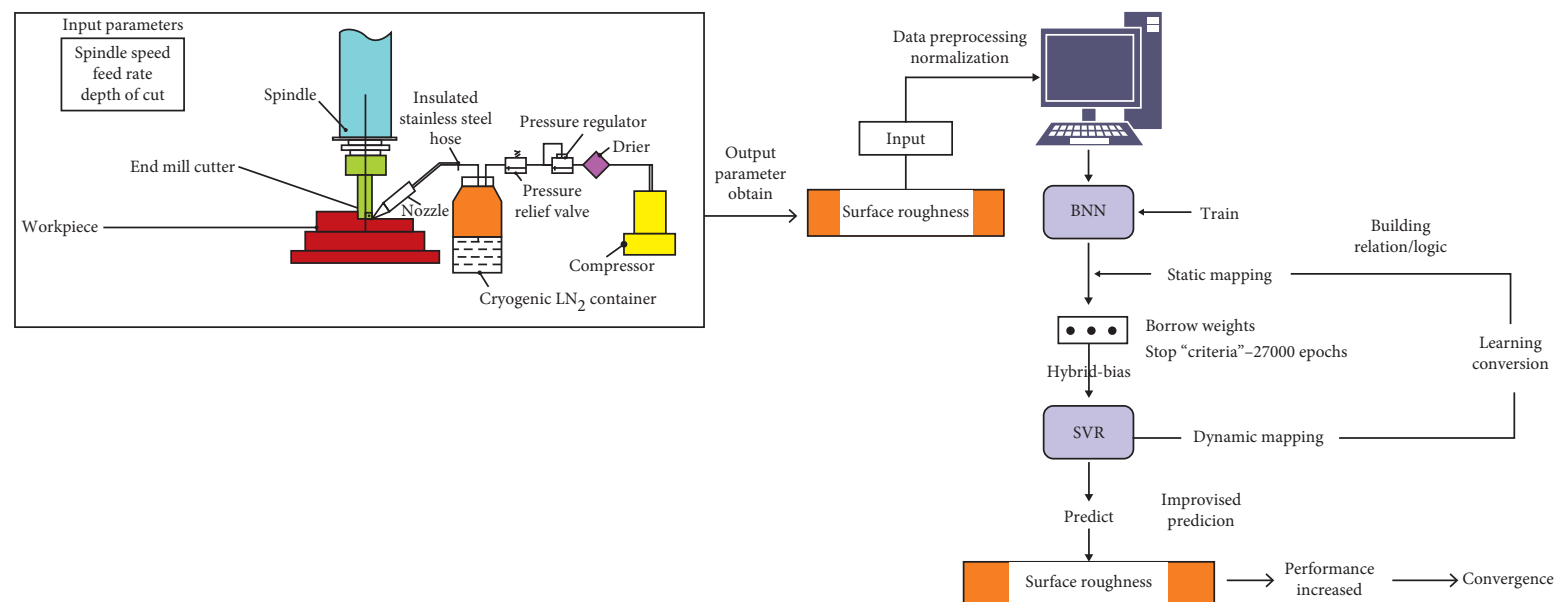

(b)

FIgURE 6: (a) Cryogenic schematic machining setup. (b) Flowchart of the proposed method "hybrid-bias (BNN-SVR).

These support vectors are dependent on the value of epsilon $\varepsilon$, and regression function smoothness is directly proportional to increase epsilon $\varepsilon$. Similarly, the model complexity and empirical error trade of cost are identified by the capacity $(C)$. Four different kernel functions such as linear, polynomial, radial, and sigmoidal were utilized in the present study.

Since the radial-based kernel function provided better results than the rest kernel functions, the radial kernel function was chosen as the best kernel for this study. $C$ is the regularization parameter, and $C$ identifies the trade-off between maximizing the margin and minimizing the training error. The effective way to identify the optimized parameter $C$ and epsilon $(\varepsilon)$ is to utilize the K-fold cross-validation or grid search method. In the current study, to identify the optimized parameter, $\mathrm{K}$-fold method is incorporated. The parameters $C$ and $\varepsilon$ were selected based on the objective to triggers the best performance results. $C=8$ and $\varepsilon=0.19$ played a significant role in achieving the required accurate predicted values. The leave-one-out (LOO) was incorporated to determine the parameters epsilon $(\varepsilon)$ and the kernel parameter sigma $(\sigma)$. Before starting the LOO procedure, the parameters $\varepsilon$ and $C$ must be set constant as 0.19 and 8 for $\varepsilon$ and $C$, respectively.
As per the above parameter value, the procedure LOO was proceeded to find the kernel parameter $\sigma$, which decreases the mean square error (MSE). In the current study, the minimal MSE attained at $\sigma=2.4$. Later on, to reduce the MSE, the same procedure was carried out to find epsilon $\varepsilon$ by setting $\sigma=2.4$. From the attained graph, it is seen that $\varepsilon=0.19$ contributes to the minimum MSE value. The result attained for the kernel parameters $\sigma$ and $\varepsilon$ by the LOO procedure is represented in Figures 10(a) and 10(b).

Hence, after finding $\sigma$ and $\varepsilon$, the SVM model follows the self-learning technique. The accuracy of the SVM model with prediction ability for the unseen data is depicted in Figures 11(a) and 11(b), respectively. Based on the value of $R$, the generalization ability and model capacity to learn can be determined. Thus, as $R$ 's value is reaching 1 , it indicates the model is adequate, accurate, and well learned in training and testing.

\section{Results and Discussions}

Altogether 55 experiments were carried out, and out of them, 45 datasets were utilized for training and 10 datasets for testing for both BNN and SVM models. The dataset is divided into 2 categories: training (82\%) and testing (18\%) [53]. To validate the developed model (RA, BNN, and SVM), 


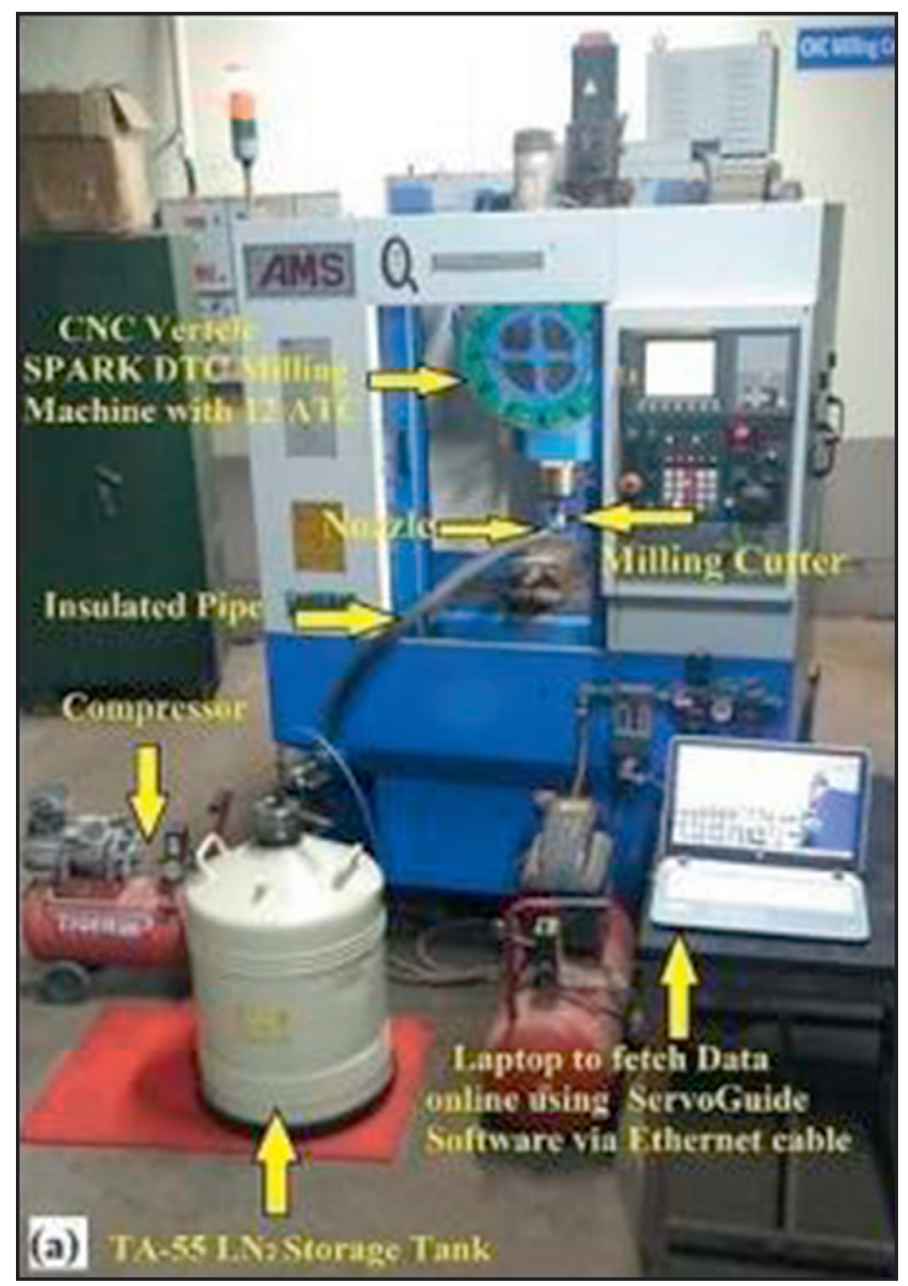

(a)

Figure 7: Continued. 


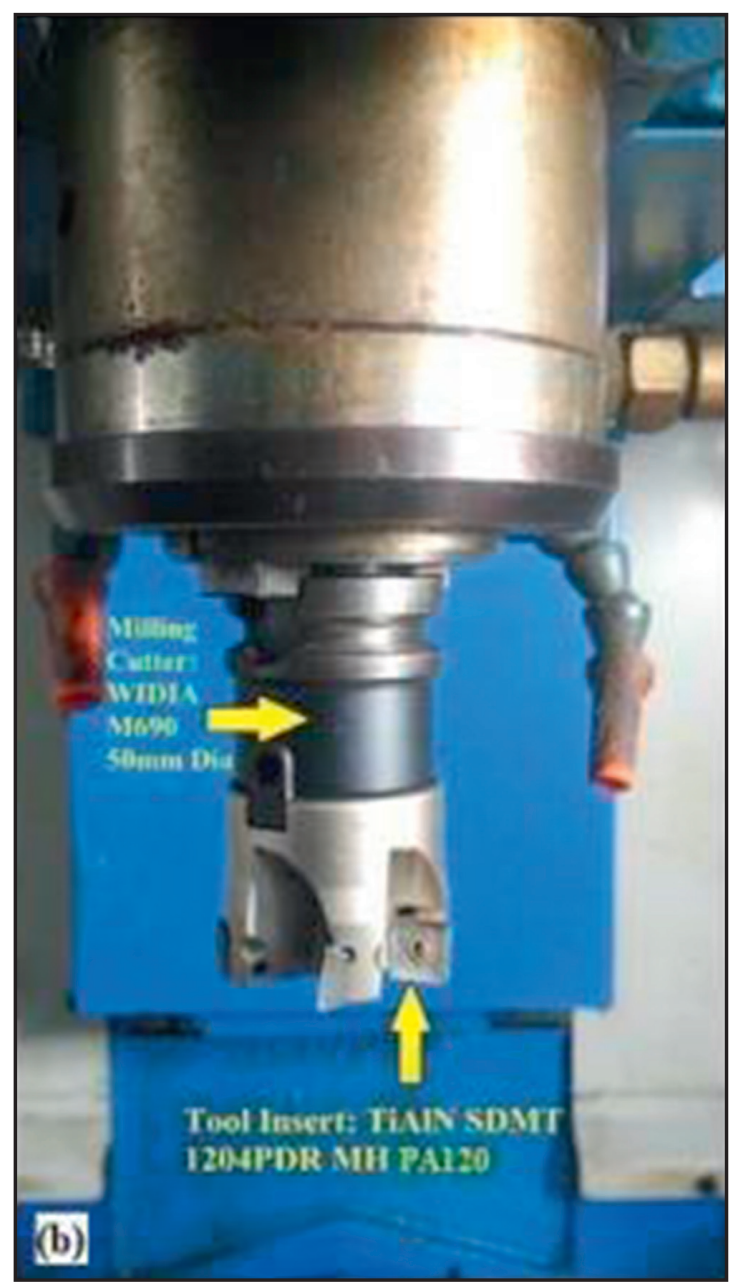

(b)

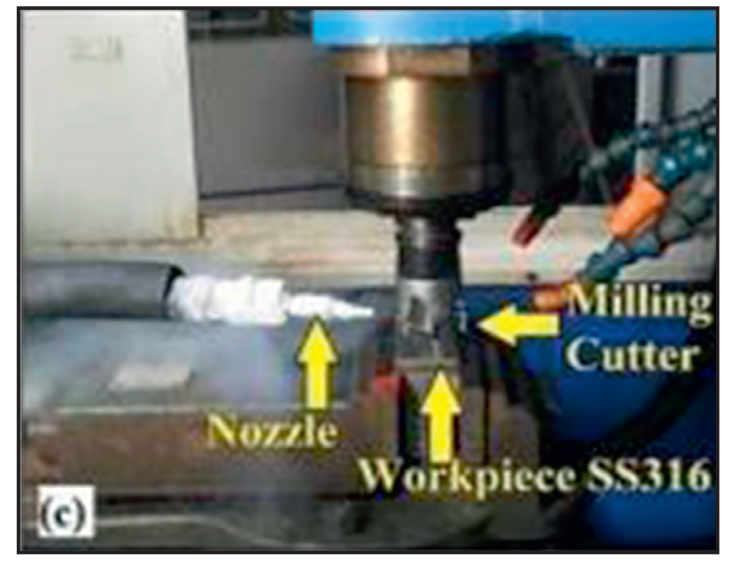

(c)

Figure 7: Continued. 


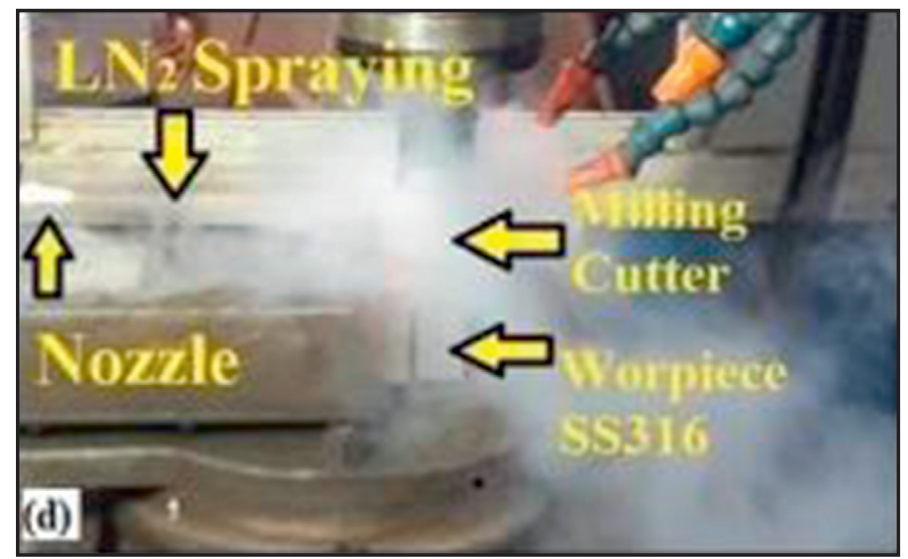

(d)

FiguRE 7: Cryogenic experimental setup with a start to end experimental instances. (a) Full cryogenic experimental setup used with different components, (b) experimentally used milling cutter and tool inserts with specifications, (c) nozzle positioned to the machining zone before the cryogenic machining, and (d) $\mathrm{LN}_{2}$ sprayed to the machining zone during the cryogenic machining experiments.

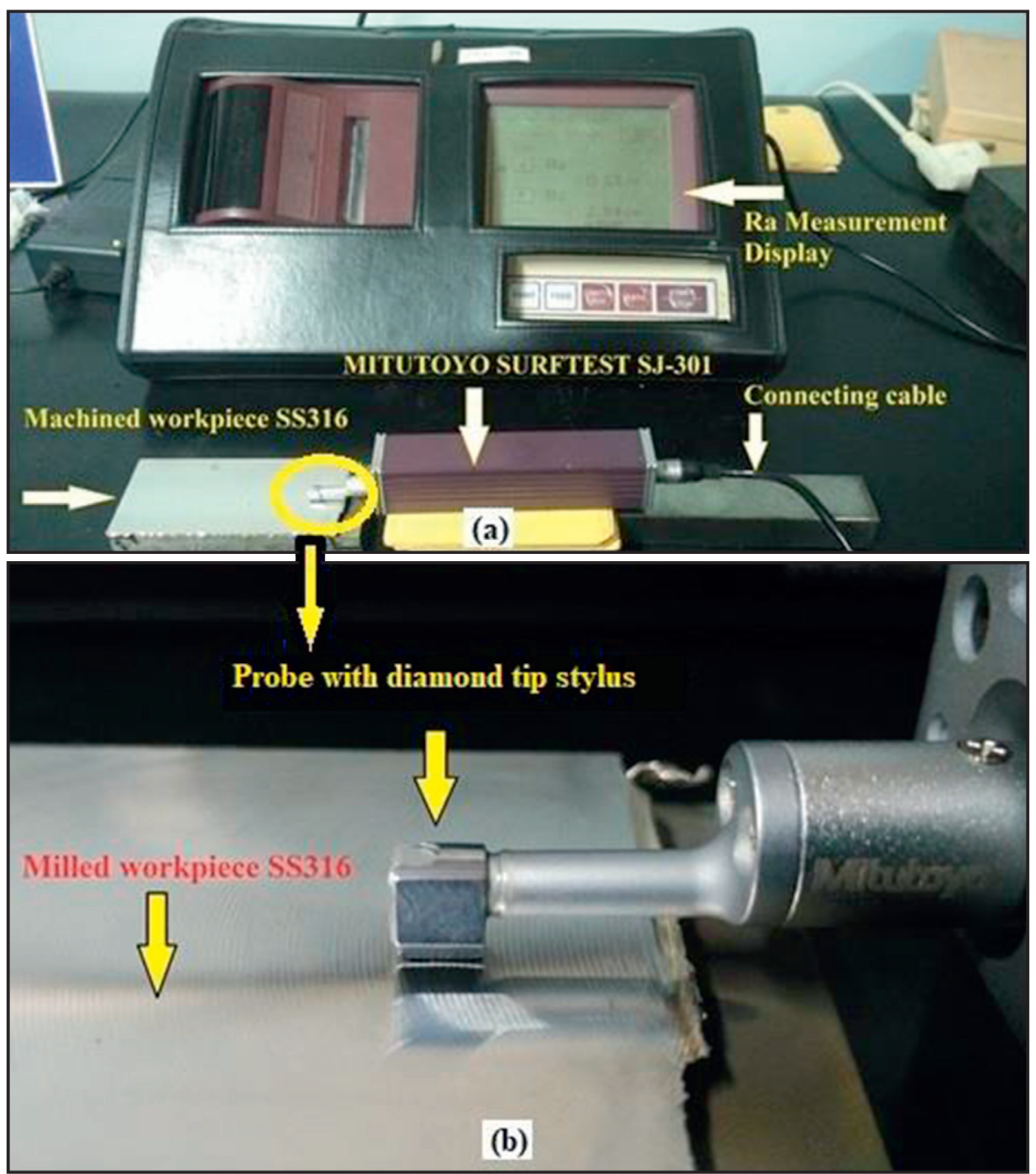

FIGURE 8: Surface roughness tester (MITUTOYO SURFTEST SJ-301) setup. (a) Surface roughness tester measuring Ra of milled workpiece SS316. (b) Expanded view of the probe with diamond tip stylus of surface roughness tester. 


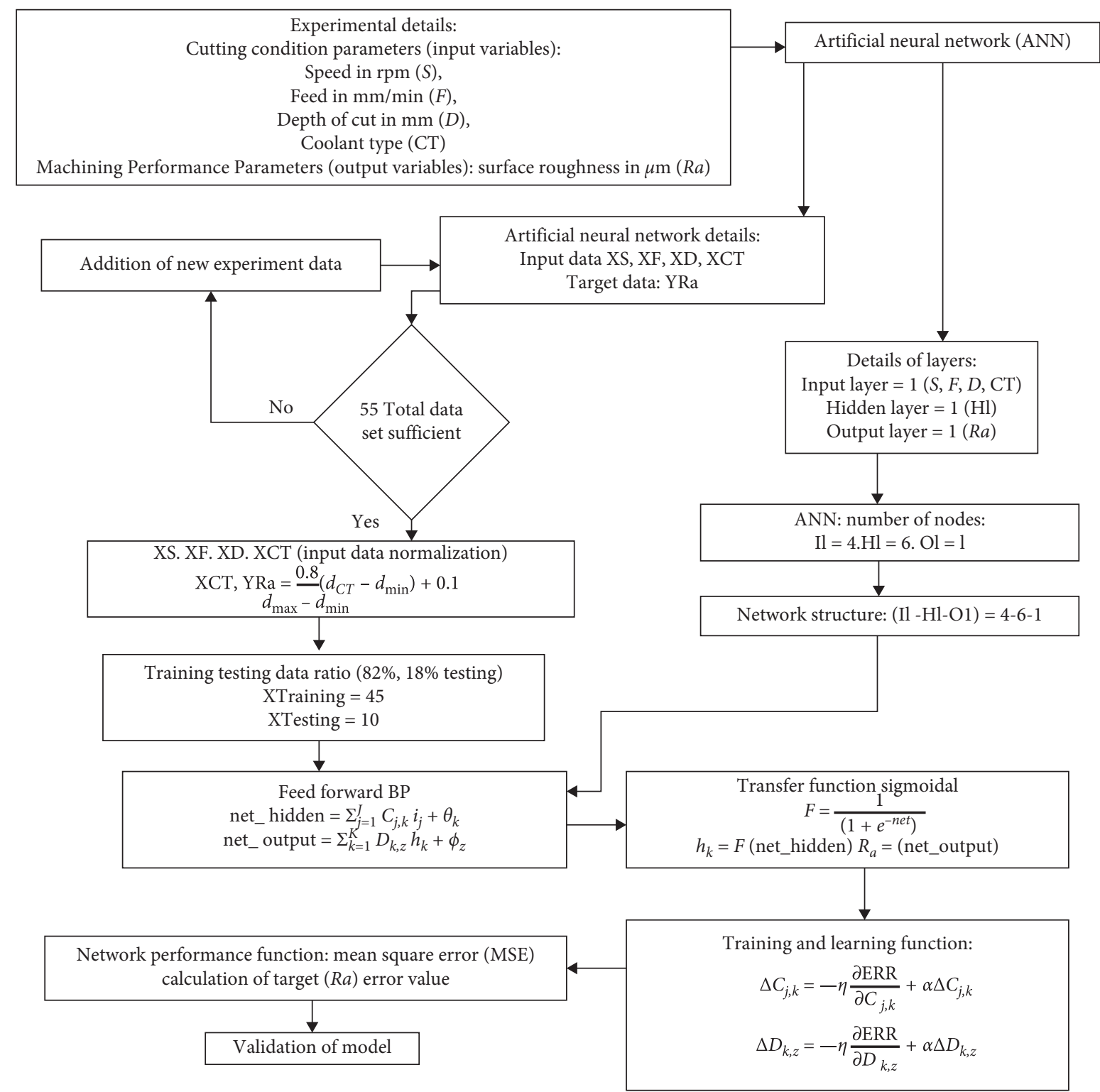

FIGURE 9: ANN model flow of work.

additional 9 experiments were conducted. A similar comparative study with a prediction model has been made between four different types of backpropagation algorithms in ANN, and the results were compared with the statistical prediction model of RSM. The attained results of 9 test cases for RA, BNN, and SVM model are depicted in Table 4, and the data is associated with Figures 12 and 13 with percentage error in $\mathrm{Ra}$ and deviation in $\mathrm{Ra}$ among prediction models RSM, BNN, and SVR, respectively.

The achieved RA (RSM) equation for surface roughness ( $\mathrm{Ra}$ ) is represented as in equation (4) [39]; by the substitution of values of Table 2, the training data is generated.

$$
\begin{aligned}
R a= & 1.23988-0.193944 * S+0.137611 * F+0.0157778 * D-0.585556 * \mathrm{CT}-0.0370733 * S * S \\
& -0.0310733 * F * F+0.0104267 * D * D+0.191427 * \mathrm{CT} * \mathrm{CT}-0.00300000 * S * F+0.00487500 * S * D \\
& +0.112250 * S * \mathrm{CT}-0.00325000 * F * D-0.0498750 * F * \mathrm{CT}+0.00400000 * D * \mathrm{CT},
\end{aligned}
$$

where $S, F, D$, and CT are the spindle speed, feed rate, doc, and coolant type individual parameters, respectively, and remaining parameter combinations are the interaction among terms. 


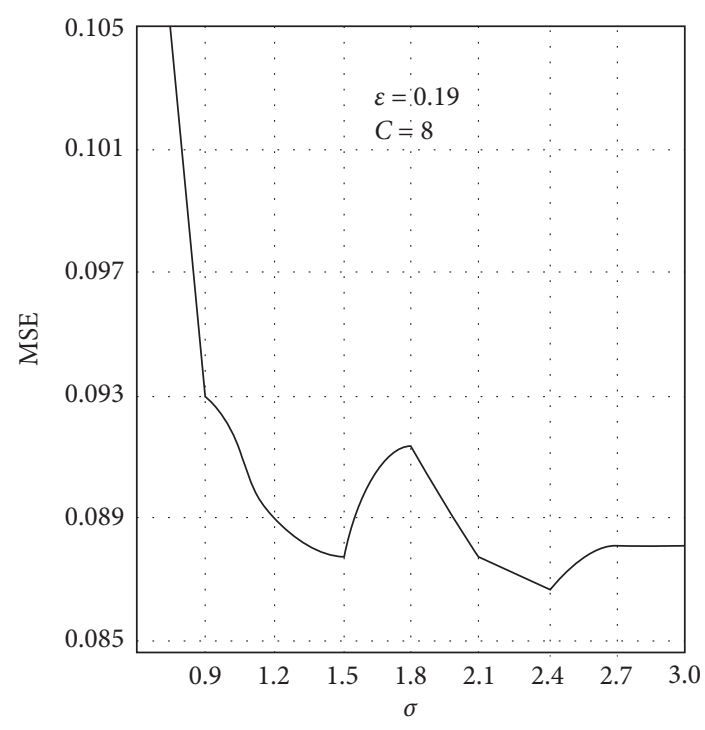

(a)

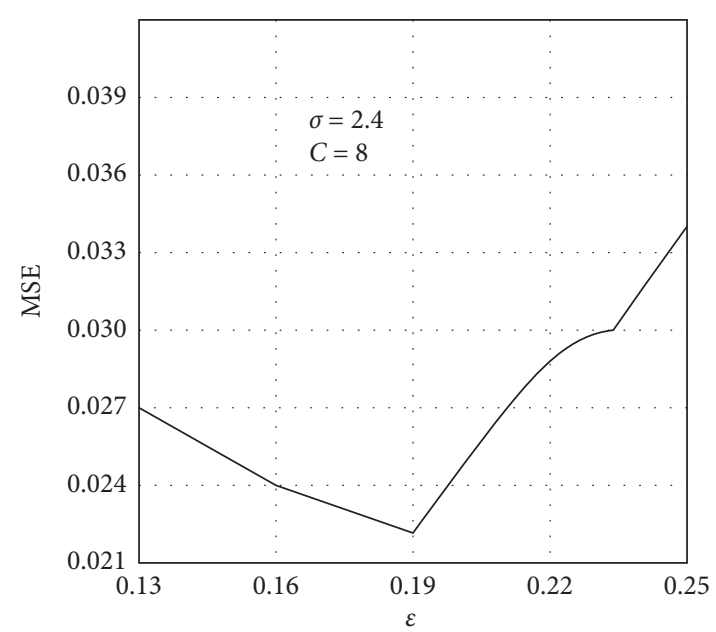

(b)

Figure 10: Effects of leave-one-out (LOO) technique in findings of kernel parameter $\sigma$ (a) and parameter $\varepsilon$ (b).

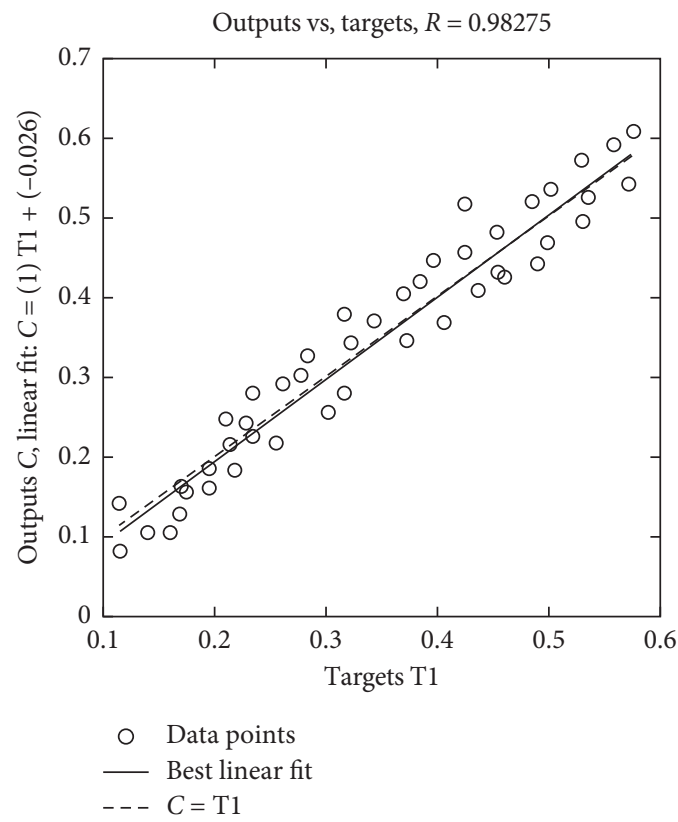

(a)

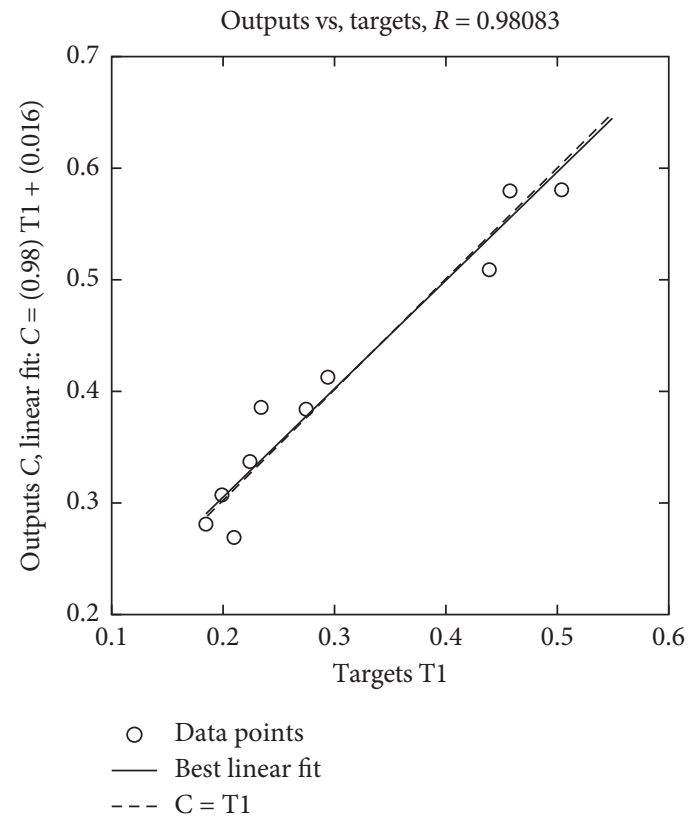

(b)

FIGURE 11: Effects of SVR on training (a) and testing (b).

The attained hyperparameter value is alpha $(\alpha)=2.65$ and beta $(\beta)=21.35$. The attained $R$ values for both the training and testing are 0.98275 and 0.98083 , respectively, as shown in Figures 11(a) and 11(b).

The authentication for the models RA, BNN, and SVM approaches has been performed with testing dataset. In order to decide the practical model, the relative errors attained via RA, BNN, and SVM results are compared with each other, and the best suitable model was identified. The result attained from Figure 12 infers that the SVM model was more suitable for the current study, while the rest of the two models RA and BNN were identical in terms of their relative errors [22]. Later on, the simulation of the forecast was carried out by a one-factor approach as represented by keeping the one parameter constant and varying the rest two. The results obtained through all 3 models, i.e., RA, BNN, and SVR, are represented in Figures 12 and 13. The SVM model results are represented in Figure 11(a) for training and in 
TABLE 4: Percentage error in Ra and deviation in Ra among prediction models RSM, BNN, and SVR compared to experimental results.

\begin{tabular}{|c|c|c|c|c|c|c|c|c|c|}
\hline \multirow[t]{2}{*}{ SL. no } & \multicolumn{3}{|c|}{ Experimental } & \multicolumn{3}{|c|}{$\begin{array}{l}\text { The percentage error in surface } \\
\text { roughness ( } \mathrm{Ra} \text { in } \mu \mathrm{m})\end{array}$} & \multicolumn{3}{|c|}{$\begin{array}{c}\text { Deviation in surface roughness } \\
(\mathrm{Ra})\end{array}$} \\
\hline & $S(\mathrm{rpm})$ & $F(\mathrm{~mm} / \mathrm{min})$ & $D(\mathrm{~mm})$ & RSM & $\mathrm{BNN}$ & SVR & RSM & BNN & SVR \\
\hline 1 & 1000 & 350 & 1 & 8.09 & 5.88 & 2.21 & 1.47 & 1.44 & 1.39 \\
\hline 2 & 1000 & 450 & 1 & 3.95 & 2.26 & 1.13 & 1.84 & 1.81 & 1.79 \\
\hline 3 & 1000 & 550 & 1 & 8.29 & 2.59 & 1.04 & 2.09 & 1.98 & 1.95 \\
\hline 4 & 2000 & 350 & 1 & 7.14 & 4.46 & 1.79 & 1.2 & 1.17 & 1.14 \\
\hline 5 & 2000 & 450 & 1 & 5.71 & 3.57 & 2.86 & 1.32 & 1.45 & 1.36 \\
\hline 6 & 2000 & 550 & 1 & 5.39 & 2.99 & 2.4 & 1.76 & 1.62 & 1.71 \\
\hline 7 & 3000 & 350 & 1 & 8.43 & 4.82 & 3.61 & 0.9 & 0.87 & 0.8 \\
\hline 8 & 3000 & 450 & 1 & 7.14 & 3.97 & 1.59 & 1.35 & 1.31 & 1.28 \\
\hline 9 & 3000 & 550 & 1 & 6.52 & 4.35 & 2.17 & 1.47 & 1.44 & 1.35 \\
\hline
\end{tabular}

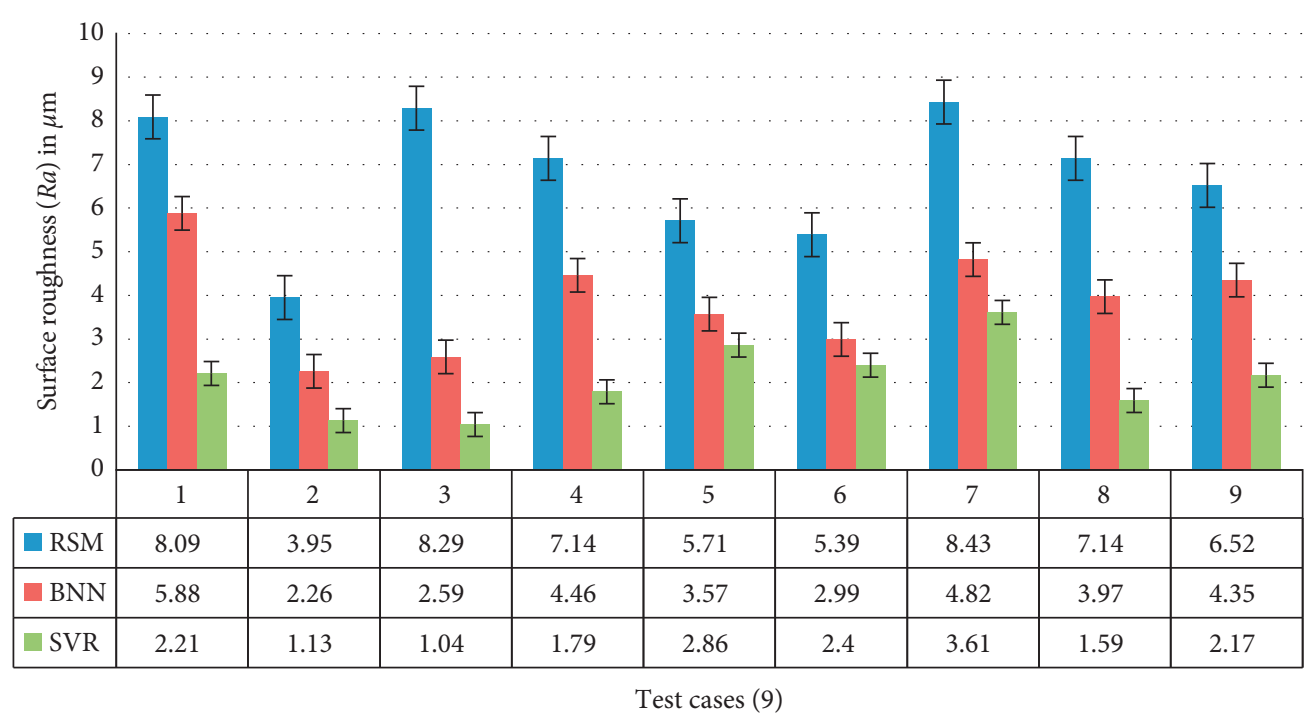

FIGURE 12: The predicted percentage of error for Ra among prediction models.

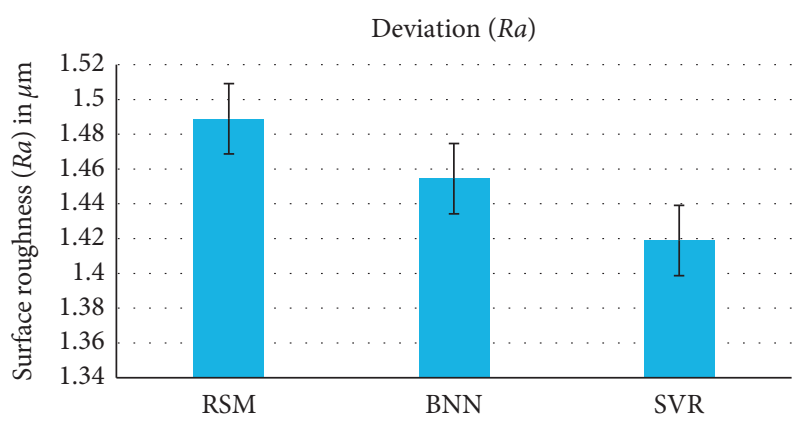

FIgURE 13: The predicted Ra deviation comparison among RA, BNN, and SVR.

Figure 11(b) for testing datasets. The value of $R$ is constrained with forced precision to have an accurate numerical value, i.e., $R=0.98275$ and $R=0.98083$, as represented in Figures 11(a) and 11(b), respectively. In the current study, the response for surface roughness $(\mathrm{Ra})$ is illustrated. The comparison of the experimental results obtained among three different machining methods, such as conventional dry, wet, and cryogenic $\left(\mathrm{LN}_{2}\right)$, is depicted in Figure 4. The $\mathrm{Ra}$ results attained via a one-factor approach, i.e., the influence of the cryogenic $\left(\mathrm{LN}_{2}\right)$ method on conventional dry and wet machining conditions, are represented in Figure 5.

Figure 14 depicts the variation of $\mathrm{Ra}$ using one parametric approach (OFA), i.e., varying feed rate and doc and by keeping constant spindle speed of $2000 \mathrm{rpm}$. The feed rate varied with low, medium, and high operating ranges, as mentioned in Table 2, i.e., $350 \mathrm{~mm} / \mathrm{min}, 450 \mathrm{~mm} / \mathrm{min}$, and 


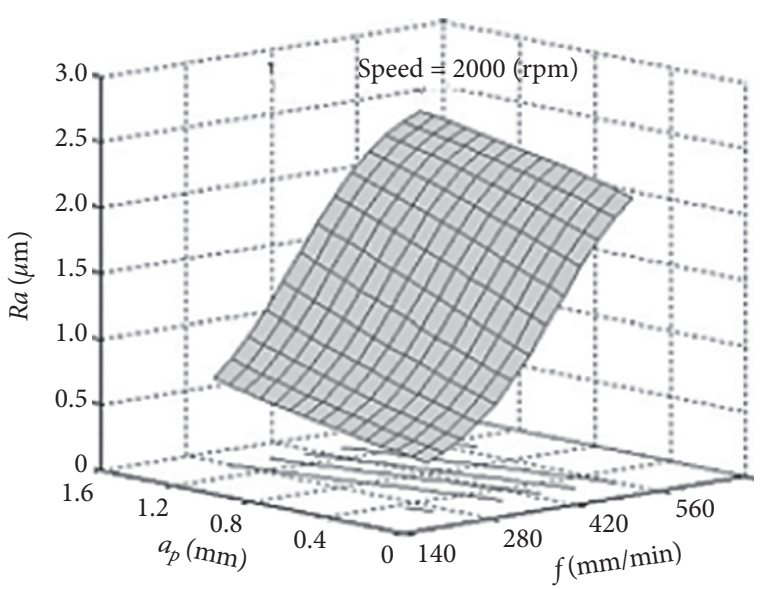

FIGURE 14: Influence of feed rate and doc on Ra for constant spindle speed of $2000 \mathrm{rpm}$.

$550 \mathrm{~mm} / \mathrm{min}$, respectively. Similarly, the doc is varied to $0.5 \mathrm{~mm}, 1 \mathrm{~mm}$, and $1.5 \mathrm{~mm}$. It is illustrated from Figure 14 that both the parameters feed rate and doc have an impact on Ra. But comparatively, the feed rate is more influential and governing on Ra.

Figure 15 represents the impact of varying feed rate and spindle speed by keeping doc constant as $1 \mathrm{~mm}$. In this case, constant doc $1 \mathrm{~mm}$ preserved and varied remaining input parameters such as spindle speed $1000 \mathrm{rpm}, 200 \mathrm{rpm}$, and $3000 \mathrm{rpm}$ and feed rate $350 \mathrm{~mm} / \mathrm{min}, 450 \mathrm{~mm} / \mathrm{min}$, and $550 \mathrm{~mm} / \mathrm{min}$. From Figure 15, it can be analyzed that the variation in response $\mathrm{Ra}$ is directly affected by feed rate and indirectly affected by spindle speed, informing, the feed rate plays an influential impact on response Ra than that of spindle speed.

Figure 16 represents the variation of response $\mathrm{Ra}$ with varying spindle speed and doc by keeping the constant feed rate of $450 \mathrm{~mm} / \mathrm{min}$. The variable parameters, i.e., spindle speed, altered between $1000 \mathrm{rpm}, 2000 \mathrm{rpm}$, and $3000 \mathrm{rpm}$ and doc as $0.5 \mathrm{~mm}, 1 \mathrm{~mm}$, and $1.5 \mathrm{~mm}$. From Figure 16, it can be seen that $\mathrm{Ra}$ is indirectly and directly proportional to spindle speed and doc, respectively.

Generally, the variation in $\mathrm{Ra}$ is indirectly proportional to input parameters, and this is due to the type of chip formation and BUE that occurred during the machining process. Usually, deteriorating $\mathrm{Ra}$ is achieved if there is a formation of continuous chips during machining. The continuous chips act as an obstacle to the coolant to reach the machining zone. As a result, the excess cutting temperature is developed in the case of wet machining. But in the case of cryogenic machining, the coolant $\mathrm{LN}_{2}$ absorbs the excess heat and makes the chips brittle easy to break the chips in nature during machining. The break-in chip process allows the coolant $\mathrm{LN}_{2}$ to reach the machining zone and restrict the development of excess cutting temperature [31, 40-42]. The chip color depends on the type of machining method adopted, such as dry, wet, or cryogenic, and input parameter variations, and the cutting temperature developed during machining. Furthermore, as per research, increasing the spindle speed, feed rate, and depth of cut

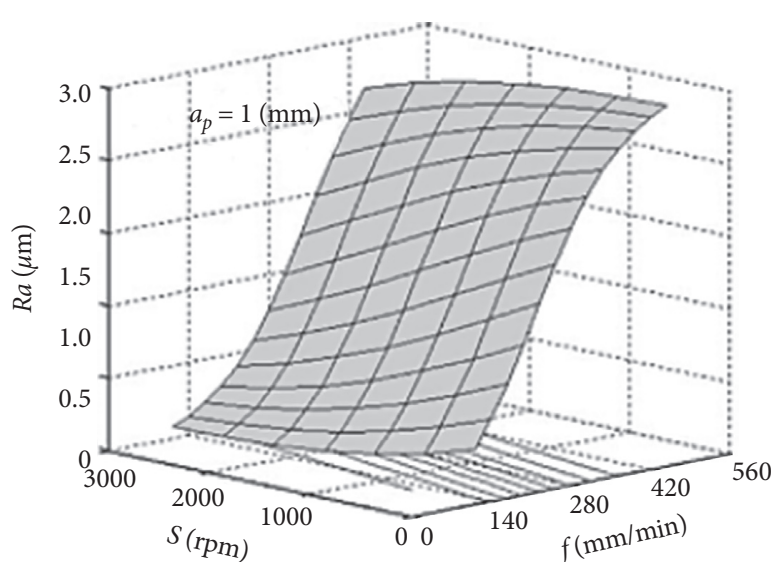

FIgURE 15: Influence of feed rate and spindle speed on Ra for constant doc of $1 \mathrm{~mm}$.

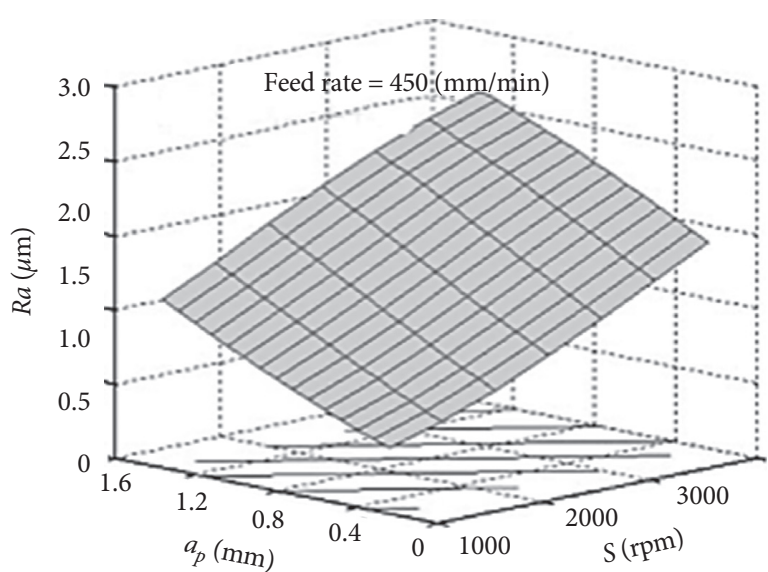

Figure 16: Result of spindle speed and doc on Ra for a constant feed rate of $450 \mathrm{~mm} / \mathrm{min}$.

could cause tool wear by maintaining the deteriorating value of $\mathrm{Ra}[7,9]$.

The feed rate acts as a vital parameter in association with $\mathrm{Ra}$. The variation of $\mathrm{Ra}$ is directly proportional to the feed 
TABle 5: Analysis of different activation functions for training and testing.

\begin{tabular}{|c|c|c|c|c|c|c|}
\hline \multirow[b]{2}{*}{$\begin{array}{l}\text { Sl. } \\
\text { no. }\end{array}$} & \multirow[b]{2}{*}{ Output } & \multirow[b]{2}{*}{$\begin{array}{l}\text { Network } \\
\text { structure }\end{array}$} & \multicolumn{4}{|c|}{ RMS error } \\
\hline & & & $\begin{array}{l}\text { Gradient descent w/momentum } \\
\text { and adaptive learning }\end{array}$ & $\begin{array}{l}\text { Scaled conjugate } \\
\text { gradient descent }\end{array}$ & Levenberg-Marquart & $\begin{array}{l}\text { Bayesian } \\
\text { regularization }\end{array}$ \\
\hline 1 & $\begin{array}{l}\text { Surface roughness } \\
\qquad \mathrm{Ra}(\mu \mathrm{m})\end{array}$ & $3-5-1$ & 9.0338 & 8.0692 & 8.9047 & 7.355 \\
\hline 2 & $\begin{array}{l}\text { Cutting force } F x \\
(\mathrm{~N})\end{array}$ & $3-5-1$ & 6.3874 & 7.5351 & 4.7693 & 3.3894 \\
\hline 3 & $\begin{array}{c}\text { Cutting } \\
\text { temperature }\left({ }^{\circ} \mathrm{C}\right)\end{array}$ & $3-5-1$ & 7.0313 & 5.6074 & 4.4586 & 4.0291 \\
\hline 4 & $\begin{array}{c}\text { Flank wear, } V b \\
(\mu \mathrm{m})\end{array}$ & $3-5-1$ & 6.2390 & 6.0197 & 5.5612 & 5.0764 \\
\hline
\end{tabular}

rate. The selection of the range of feed-rate must be decided accurately, as it has a more significant impact on Ra; an increase in feed rate leads to an increase of output responses such as cutting force, tool deflections, chipping, tool wear [32]. But the doc has an indirect influence on $\mathrm{Ra}$ via the formation of BUE, cutting temperature, chip deformation, and cutting force $[39,44]$. SVM, NN, and RA methodologies were used to predict and optimize RA and cutting force in milling.

An activation function was entirely chosen based on the requirement of study by conducting trial and error methods. Later on, the choosing factor was on the RMS error attained through respective functions. BNN model attained better performance than GD, SCGD, and LM due to its adaptability and convergence features. Thus, the BNN BPA method was more practical to predict as it attained less deviation percentage for the considered dataset. The deviation percentage attained for predicting Ra by the statistical (RSM) and NN based (GD, SCGD, LM, and BNN) approaches lies as follows: RSM: 9.43\%-6.78\%, GD: 9.03\%-6.213\%, SCGD: 8.06\%-5.60\%, LM: $8.90 \%-4.45 \%$ and BNN: $7.35 \%-3.38 \%$.

\section{Conclusions}

The variation and effects of variables such as feed rate, spindle speed, cooling type, and doc on $\mathrm{Ra}$ in face milling operation with different cooling techniques are examined in the current study.

(1) The comparative analysis of $\mathrm{LN}_{2}$ over Dry and $\mathrm{LN}_{2}$ over Wet machining conditions revealed that $\mathrm{LN}_{2}$ machining yielded better surface finish with up to $64.9 \%, 54.9 \%$ over dry and wet machining, respectively, the benefit of $\mathrm{LN}_{2}$ for achieving better Ra.

(2) The benchmark functions demonstrate that the hybrid-bias (BNN-SVR) algorithm can fall out of the local minimum and converge to the optimal global value.

(3) The performance of the (BNN-SVR) is a prevalent new ability to fetch the partially trained weights from the BNN model into the SVR model, thus leading to conversion of static learning capability to dynamic capability. The performance of hybrid-bias (BNNSVR) surpasses the performance of BNN and RSM by achieving greater convergence and less deviation error.
(4) The SVR model is chosen as the best suitable method, based on its convergence characteristic and computational time. The statistical significance of the model is expressed in terms of its performance, that is, the error percentage achieved. The deviations attained by the models are as follows:

RSM: $3.95 \%-8.43 \%$, BNN: $2.36 \%-5.88 \%$, SVR: $1.04 \%-3.61 \%$

All three models have a deviation percentage below $10 \%$. It was found that the neural network approach BNN and machine learning model hybrid-bias (BNN-SVR) algorithm correlate well with experimental results. But the best prediction for response Ra was attained by the SVR model with the maximum deviation percentage of $3.61 \%$.

\section{Data Availability}

The data used to support the findings of this study are available from the corresponding author, or available within the article, upon request.

\section{Conflicts of Interest}

The authors declare that they have no conflicts of interest.

\section{Acknowledgments}

The authors would like to thank the National Institute of Technology (NITK), Department of Mechanical Engineering, for providing support and facilities.

\section{References}

[1] H. A. Hegab, B. Darras, and H. A. Kishawy, "Towards sustainability assessment of machining processes," Journal of Cleaner Production, vol. 170, no. 1, pp. 694-703, 2018.

[2] N. Khanna, P. Shah, R. W. Maruda, G. M. Krolczyk, and H. Hegab, "Experimental investigation and sustainability assessment to evaluate environmentally clean machining of 15-5 PH stainless steel," Journal of Manufacturing Processes, vol. 56, pp. 1027-1038, 2020.

[3] N. Khanna, P. Shah, J. Wadhwa, A. Pitroda, J. Schoop, and F. Pusavec, "Energy consumption and lifecycle assessment comparison of cutting fluids for drilling titanium alloy," Procedia CIRP, vol. 98, pp. 175-180, 2021.

[4] P. Shah, P. Bhat, and N. Khanna, "Life cycle assessment of drilling inconel 718 using cryogenic cutting fluids while 
considering sustainability parameters," Sustain Energy Technol Assessments, vol. 43, 2021.

[5] K. Giasin, A. Dad, E. Brousseau, U. Koklu, S. Morkavuk, and M. Mia, "The effects of through tool cryogenic machining on the hole quality in GLARE ${ }^{\circledR}$ fibre metal laminates," Journal of Manufacturing Processes, vol. 64, pp. 996-1012, 2021.

[6] U. Koklu, "The drilling machinability of 5083 aluminum under shallow and deep cryogenic treatment," Emerging Materials Research, vol. 9, pp. 323-330, 2020.

[7] N. Khanna, C. Agrawal, D. Yu Pimenov et al., "Review on design and development of cryogenic machining setups for heat resistant alloys and composites," Journal of Manufacturing Processes, vol. 68, pp. 398-422, 2021.

[8] M. Danish, T. L. Ginta, A. M. Abdul Rani et al., "Investigation of surface integrity induced on AZ31C magnesium alloy turned under cryogenic and dry conditions," Procedia Manufacturing, vol. 41, pp. 476-483, 2019.

[9] N. Khanna, C. Agrawal, M. K. Gupta, Q. Song, and A. K. Singla, "Sustainability and machinability improvement of Nimonic-90 using indigenously developed green hybrid machining technology," Journal of Cleaner Production, vol. 263, Article ID 121402, 2020.

[10] T. Patel, N. Khanna, S. Yadav, P. Shah, M. Sarikaya, and D. Singh, "Machinability analysis of nickel-based superalloy Nimonic 90: a comparison between wet and LCO2 as a cryogenic coolant," International Journal of Advanced Manufacturing Technology, vol. 113, 2021.

[11] W. Zhao, L. Gong, F. Ren, L. Li, Q. Xu, and A. M. Khan, "Experimental study on chip deformation of Ti-6Al-4V titanium alloy in cryogenic cutting," International Journal of Advanced Manufacturing Technology, vol. 96, pp. 4021-4027, 2018.

[12] W. Zhao, F. Ren, A. Iqbal, L. Gong, N. He, and Q. Xu, "Effect of liquid nitrogen cooling on surface integrity in cryogenic milling of Ti-6Al-4V titanium alloy," International Journal of Advanced Manufacturing Technology, vol. 106, pp. 1497-1508, 2020.

[13] M. Jamil, N. He, W. Zhao et al., "Heat transfer efficiency of cryogenic- $\mathrm{LN}_{2}$ and $\mathrm{CO}_{2}$-snow and their application in the turning of Ti-6AL-4V," International Journal of Heat and Mass Transfer, vol. 166, Article ID 120716, 2021.

[14] M. Jamil, W. Zhao, N. He, M. K. Gupta, M. Sarikaya, and A. M. Khan, "Sustainable milling of Ti-6Al-4V: a trade-off between energy efficiency, carbon emissions and machining characteristics under MQL and cryogenic environment," Journal of Cleaner Production, vol. 281, Article ID 125374, 2021.

[15] A. K. Gupta, "Predictive modelling of turning operations using response surface methodology artificial neural networks and support vector regression," International Journal of Manufacturing Technology and Management, vol. 48, pp. 763-778, 2010.

[16] H. Oktem, T. Erzurumlu, and H. Kurtaran, "Application of response surface methodology in the optimization of cutting conditions for surface roughness," Journal of Materials Processing Technology, vol. 170, pp. 11-16, 2005.

[17] B. Lela, D. Bajic, and J. Sonja, "Regression analysis, support vector machines, and Bayesian neural network approaches to modeling surface roughness in face milling," International Journal of Advanced Manufacturing Technology, vol. 42, pp. 1082-1088, 2009.

[18] X. Feng, R. F. Tufail, and M. Zahid, "Experimental investigation and statistical modeling of FRP confined RuC using response surface methodology," Civil Engineering Journal, vol. 5, p. 268, 2019.

[19] C. Lu, "Study on prediction of surface quality in machining process," Journal of Materials Processing Technology, vol. 205, pp. 439-450, 2008.

[20] I. O. Alade, M. A. Abd Rahman, and T. A. Saleh, "Modeling and prediction of the specific heat capacity of $\mathrm{Al}_{2} \mathrm{O}_{3}$ /water nanofluids using hybrid genetic algorithm/support vector regression model," Nano-Structures and Nano-Objects, vol. 17, pp. 103-111, 2019.

[21] J. Dong, K. V. R. Subrahmanyam, Y. S. Wong, G. S. Hong, and A. R. Mohanty, "Bayesian-inference-based neural networks for tool wear estimation," International Journal of Advanced Manufacturing Technology, vol. 30, pp. 797-807, 2006.

[22] S. Cho, S. Asfour, A. Onar, and N. Kaundinya, "Tool breakage detection using support vector machine learning in a milling process," International Journal of Machine Tools and Manufacture, vol. 45, pp. 241-249, 2005.

[23] Y. W. Hsueh and C. Y. Yang, "Tool breakage diagnosis in face milling by support vector machine," Journal of Materials Processing Technology, vol. 209, pp. 145-152, 2009.

[24] P. G. Benardos and G. C. Vosniakos, "Prediction of surface roughness in CNC face milling using neural networks and Taguchi's design of experiments," Robotics and ComputerIntegrated Manufacturing, vol. 18, pp. 343-354, 2008.

[25] I. A. El-Sonbaty, U. A. Khashaba, A. I. Selmy, and A. I. Ali, "Prediction of surface roughness profiles for milled surfaces using an artificial neural network and fractal geometry approach," Journal of Materials Proceesing Technology, vol. 200, 2008.

[26] M. Han and Z. J. Cao, "An improved case-based reasoning method and its application in endpoint prediction of basic oxygen furnace," Neurocomputing, vol. 149, pp. 1245-1252, 2015.

[27] J. Mathew, M. Griffin, and S. Alamaniotis, "Prediction of welding residual stresses using machine learning: comparison between neural networks and neuro-fuzzy systems," Applied Soft Computing, vol. 70, pp. 131-146, 2018.

[28] H. K. Asilturk and H. El Mounayri, "Prediction of cutting forces and surface roughness using artificial neural network (ANN) and support vector regression (SVR) in turning 4140 steel," Materials Science and Technology, vol. 28, pp. 980-986, 2012.

[29] A. Yeganefar, S. Ali Niknam, and R. Asadi, "The use of support vector machine, neural network, and regression analysis to predict and optimize surface roughness and cutting forces in milling," International Journal of Advanced Manufacturing Technology, vol. 105, pp. 951-965, 2019.

[30] G. Kiswanto, D. L. Zariatin, and T. J. Ko, "The effect of spindle speed, feed-rate and machining time to the surface roughness and burr formation of aluminum alloy 1100 in micro-milling operation," Journal of Manufacturing Processes, vol. 16, pp. 435-450, 2014.

[31] N. Agarwal, "Surface roughness modeling with machining parameters (speed, feed \& depth of cut) in CNC milling," MIT International Journal Mechanical Engineering, vol. 2, pp. 55-61, 2014.

[32] S. Kumar, I. Saravanan, and L. Patnaik, "Optimization of surface roughness and material removal rate in milling of AISI 1005 carbon steel using Taguchi approach," Materials Today Proceedings, vol. 22, pp. 654-658, 2020.

[33] S. H. Tomadi, J. A. Ghani, C. H. C. Haron, H. M. Ayu, and R. Daud, "Effect of cutting parameters on surface roughness in 
end milling of AlSi/AlN metal matrix composite," Procedia Engineering, vol. 184, pp. 58-69, 2017.

[34] Y.-C. Lin, Y.-C. Chen, K.-D. Wu, and J.-P. Hung, "Prediction of surface roughness based on the machining conditions with the effect of machining stability," Advances in Science Technology Research Journal, vol. 14, pp. 171-183, 2020.

[35] I. Hyuk and P. Sang, "Case-based reasoning and neural network based expert system for personalization," Expert Systems with Applications, vol. 32, pp. 77-85, 2007.

[36] M. Relich and P. Pawlewski, "A case-based reasoning approach to cost estimation of new product development," Neurocomputing, vol. 272, pp. 40-45, 2018.

[37] G. Ghosh, P. Mandal, and S. C. Mondal, "Modeling and optimization of surface roughness in keyway milling using ANN, genetic algorithm, and particle swarm optimization," International Journal of Advanced Manufacturing Technology, vol. 100, no. 5, pp. 1223-1242, 2019.

[38] U. Natarajan, S. Palani, and B. Anandampilai, "Prediction of surface roughness in milling by machine vision using ANFIS," Computer-Aided Design and Applications, vol. 9, no. 3, pp. 269-288, 2012.

[39] P. Sivaiah and D. Chakradhar, "Effect of cryogenic coolant on turning performance characteristics during machining of 17-4 PH stainless steel: a comparison with MQL, wet, dry machining," CIRP Journal of Manufacturing Science Technology, vol. 21, pp. 86-96, 2018.

[40] P. Sivaiah and D. Chakradhar, "Comparative evaluations of machining performance during turning of 17-4 $\mathrm{PH}$ stainless steel under cryogenic and wet machining conditions," $M a$ chining Science and Technology, vol. 22, pp. 147-162, 2018.

[41] R. L. Malghan, K. M. C. Rao, A. K. Shettigar, S. S. Rao, and R. J. D'Souza, “Application of particle swarm optimization and response surface methodology for machining parameters optimization of aluminium matrix composites in milling operation," Journal Brazilian Society Mechanics Science Engineering, vol. 39, 2017.

[42] R. Lmalghan, K. Rao, S. ArunKumar, S. S. Rao, and M. A. Herbert, "Machining parameters optimization of AA6061 using response surface methodology and particle swarm optimization," International Journal of Precision Engineering and Manufacturing, vol. 19, pp. 695-704, 2018.

[43] J. R. Davis, ASM Specialty Handbook: "tool Materials", ASM international, Geauga County, OH, USA, 1995.

[44] M. C. Karthik Rao, R. L. Malghan, S. ArunKumar, S. S. Rao, and M. A. Herbert, "An efficient approach to optimize wear behavior of cryogenic milling process of SS316 using regression analysis and particle swarm techniques," Transactions of the Indian Institute of Metals, vol. 72, pp. 191-204, 2019.

[45] M. O. Qadri and H. Namazi, "Fractal-based analysis of the relation between surface finish and machine vibration in milling operation," Fluctuation and Noise Letters, vol. 19, pp. 1-13, 2019.

[46] M. Sahaluddin, I. O. Alade, M. O. Oyedeji, and U. S. Aliyu, "A machine learning-based model to estimate the density of nanofluids of nitrides in ethylene glycol," Journal of Applied Physics, vol. 127, Article ID 205105, 2020.

[47] K. R. M. C., R. L. Malghan, A. K. Shettigar, S. S. Rao, and M. A. Herbert, "Application of back propagation algorithms in neural network based identification responses of AISI 316 face milling cryogenic machining technique," Australian Journal of Mechanical Engineering, 2020.

[48] O. Erkan, I. Birhan, A. Cicek, and F. Kara, "Prediction of damage factor in end milling of glass fibre reinforced plastic composites using artificial neural network," Applied Composite Materials, vol. 20, pp. 517-536, 2013.

[49] M. Mia and N. R. Dhar, "Optimization of surface roughness and cutting temperature in high-pressure coolant-assisted hard turning using Taguchi method," International Journal of Advanced Manufacturing Technology, vol. 88, pp. 739-753, 2017.

[50] S. Yi, J. Li, J. Zhu, X. Wang, J. Mo, and S. Ding, "Investigation of machining Ti-6Al-4V with graphene oxide nanofluids: tool wear, cutting forces and cutting vibration," Journal of Manufacturing Processes, vol. 49, pp. 35-49, 2020.

[51] V. K. Srivastava, "Chapter 2 "simple linear regression analysis," Regression Analysis, vol. 1-42, 2019, http://home.iitk.ac. in/ shalab/regression/Chapter2-Regression-SimpleLin earRegressionAnalysis.pdf.

[52] X. Chuangwen, D. Jianming, C. Yuzhen, L. Huaiyuan, S. Zhicheng, and X. Jing, "The relationships between cutting parameters, tool wear, cutting force and vibration," Advances in Mechanical Engineering, vol. 10, no. 1-14, 2018.

[53] X. Wang, Y. Yue, J. J. Faraway, X. Wang, Y. Yue, and J. J. Faraway, Bayesian Regression Modeling with INLA, CRC Press, vol. 13, Boca Raton, FL, USA, 2018. 